\title{
Noise score rating models for Q-Zones and embedded parks
}

DOI 10.1515/noise-2015-0004

Received Jul 28, 2015; accepted Oct 14, 2015

\begin{abstract}
CITYHUSH project supports city administrations in the implementation of noise action plans according to the EU directive 2002/49/EC. The action "Noise and vibration control at source - Acoustically green vehicles" validates noise score rating models in a case in the Athens area, including Q-Zones (Quiet zones) and embedded parks, identifying perceived benefits on noise. Annoyance for PTW (powered two-wheeler) is masked in general traffic annoyance. However, a PTW pass may become recognizable and clearly distinct within the traffic noise environment formed by the road traffic flow and synthesis. Several strategic noise mapping scenarios with high noise levels from PTWs, as well as low frequency noise annoyance events, were evaluated proving that the noise levels in a Q-Zone and embedded parks may be reduced with an increased park capacity. Measures with a special focus on the reduction of conventionally powered motorbikes and scooters (PTWs) were evaluated. PTW's emission values were derived, from known values and past measurements, in the form of a correction function as a function of speed to perform simulation analysis for various analogies of conventionally versus electrically driven PTWs. Relevant noise difference maps indicate noise reductions, especially when additional measures are included, such as speed limits.
\end{abstract}

Striking image

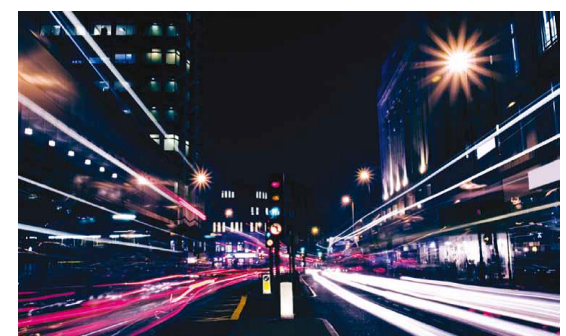

Keywords: PTW; Noise mapping; Noise annoyance; City Hush

\section{Introduction}

The CITYHUSH project will support city administrations in the production and implementation of noise action plans according to the directive 2002/49/EC [1]. The identified hot spots and noise action plans made with the existing technology suffer from major shortcomings:

(a) poor correlation between hot spots with annoyance and complaints;

(b) most measures lead to increased emissions;

(c) only indoor noise comfort is addressed.

Step change solutions are proposed to reduce noise in the city environment. The project deals with developing suitable problem identification and evaluation tools, with designing and developing solutions for hot spots, which show high correlation with annoyance and complaints. In the greater area of Athens, numerous environmental, economic, and technical challenges are also associated with other sources, such as light rapid transit (LRT) and underground metro systems. The assessment of annoyance rating and the effectiveness of various mitigation measures with respect to acceptable noise and vibration levels was recently investigated [2, 3]. Indeed, the rapid development of urban traffic both on the surface and underground requires intensive analysis and effective measures against airborne and ground-borne noise. This paper covers the validation of noise score rating models for Q-Zones and embedded parks by a case study carried out in Athens, Greece. It includes the definition of seven different Q-Zone strategic noise mapping scenarios and the simulation of their effects on average noise levels across the test site. The results are compared with environmental noise difference maps, which are correspondingly presented for daytime and evening (DE) and for the night time (N). Focus will be drawn specifically to motorbikes and scooters and the impact that a relative reduction will have on overall noise levels. A further step includes a noise score, i.e.,

Markus Petz: ACCON GmbH, Gewerbering 5, 86926, Greifenberg, Deutschland; Email: markus.petz@accon.de
^Corresponding Author: Konstantinos Vogiatzis: Faculty of Civil Engineering, Transportation Department, University of Thessaly, Pedion Areos, 38334 Volos, Greece; Email: kvogiatz@uth.gr 
the amount of highly annoyed people (HAP) and the number of annoyed park visitors, and how these correlate with the general noise levels in the various scenarios. After ten years of the approval of the Environmental Noise Directive 2002/49/EC (END), a lot of experiences have been acquired to develop strategic noise maps and noise action plans executed by the Member States within the first and second rounds of implementation of the END. Data on the estimated number of inhabitants exposed to bands of values of Lden and Lnight reported to the European Commission by Member States are available on the EIONET website and large differences from each other are observed. Due to economic constraints, a priority scale of mitigation actions is needed and, for this purpose, various legislations in EU Members States were established based on exceeding the limits and the amount of population exposed to such excess, such as the "Multi Annoyance Building Prioritisation Score (MABPS)", aimed to take into account the annoyance due to the exposure from different sources (i.e., multiexposure) [4-6]. Furthermore, the definition of a common European procedure to prioritise identification of the most critical areas and to implement the most efficient mitigation measures is a major objective for the European policy makers. Additionally, the use of a common method will allow better define common environmental noise strategies in Europe. Relevant results is expected to be achieved with all Member States adopting the new common methodology and incorporating in due time in their respective national regulations [7].

\section{The Athens test site}

Athens is the capital of Greece and includes 5,5 million inhabitants. The test site was chosen as it is situated in a densely populated area and is also popular with local citizens and tourists as a place for recreation and leisure. The chosen site can definitely, if wished, become a quiet zone in the heart of the city and be beneficial to a potential of several thousand people. The aim of the different environmental noise investigations at the "Athens validation site" (Figure 1) is to apply the evaluation tools (e.g., noise score model for residents and park visitors, capacity of embedded park, noise distribution) on traffic scenarios with different composition of the traffic fleet and different background noise level (e.g., caused by rail). After a few scenarios are proposed, some indications were obtained whether the possible noise restrictions in the Q-zone will be effective. In Figure 1, the Q-Zone (test site) and the investigated park are shown. A major urban road network runs through
Table 1: Test-site-describing attributes for Athens. Q-Zone test site.

\begin{tabular}{ll}
\hline Area test site & - \\
Area Q-Zone & $1.17 \mathrm{~km}^{2}$ \\
Area embedded park complete & $0.13 \mathrm{~km}^{2}$ \\
Area embedded park left & $0.05 \mathrm{~km}^{2}$ \\
Area emdedded park right & $0.08 \mathrm{~km}^{2}$ \\
$\begin{array}{l}\text { Number of residents with access to the park } \\
\text { (within a } 5 \text { min-walk-distance to the park) }\end{array}$ & 10316 \\
$\begin{array}{ll}\text { Number of residents within the Q-Zone } \\
\text { Number of residents within the park complete }\end{array}$ & 19547 \\
$\begin{array}{l}\text { Number of residents within the park left } \\
\text { Number of residents within the park right }\end{array}$ & 3000 \\
$\begin{array}{l}\text { Density Q-Zone (inhabitants } / \mathrm{km}{ }^{2} \text { ) } \\
\text { Number of residents within the test site }\end{array}$ & 300 \\
(outside Q-Zone L) & - \\
Density test site & - \\
(outside Q-Zone L) (inhabitants $/ \mathrm{km}^{2}$ ) & \\
\hline
\end{tabular}

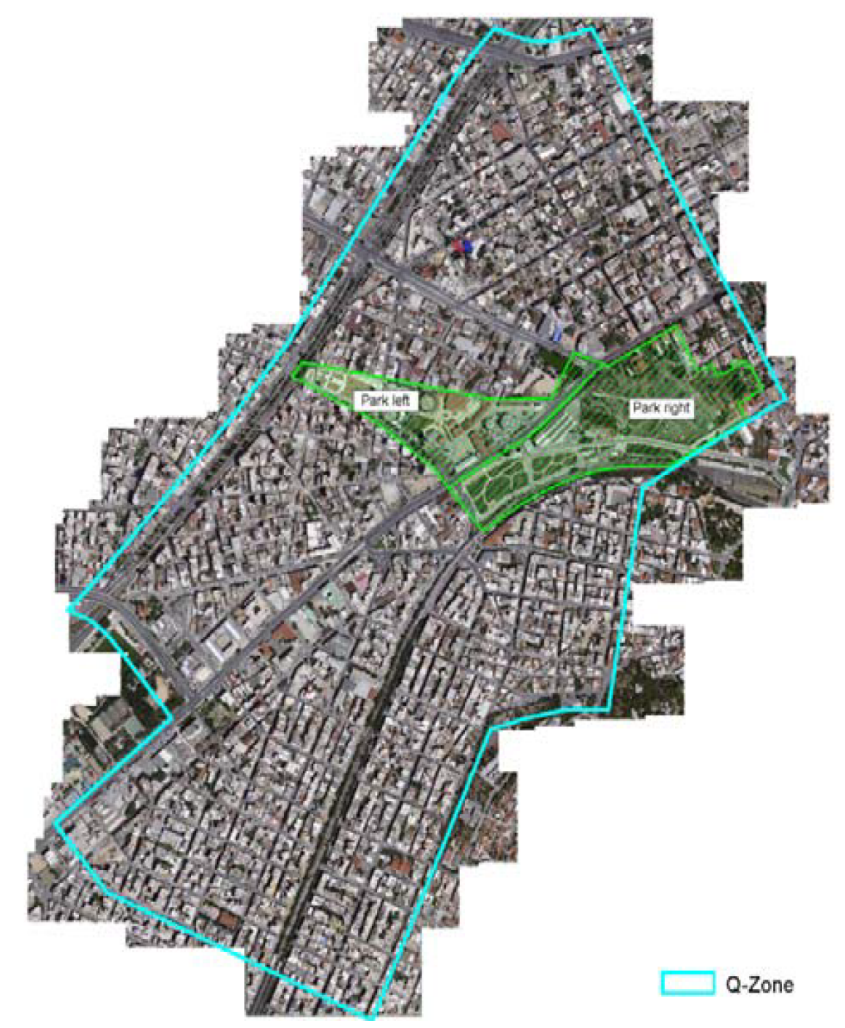

Figure 1: Q-Zone (test site) and the investigated park in Athens. The park is divided into two sections for evaluation (Park left and Park right).

the middle of the park, which is used this division to divide the park into two parts for evaluation calculations. The attributes characterising the Q-Zone are listed in Table 1. The areas of the Q-Zone and the park are divided into the 


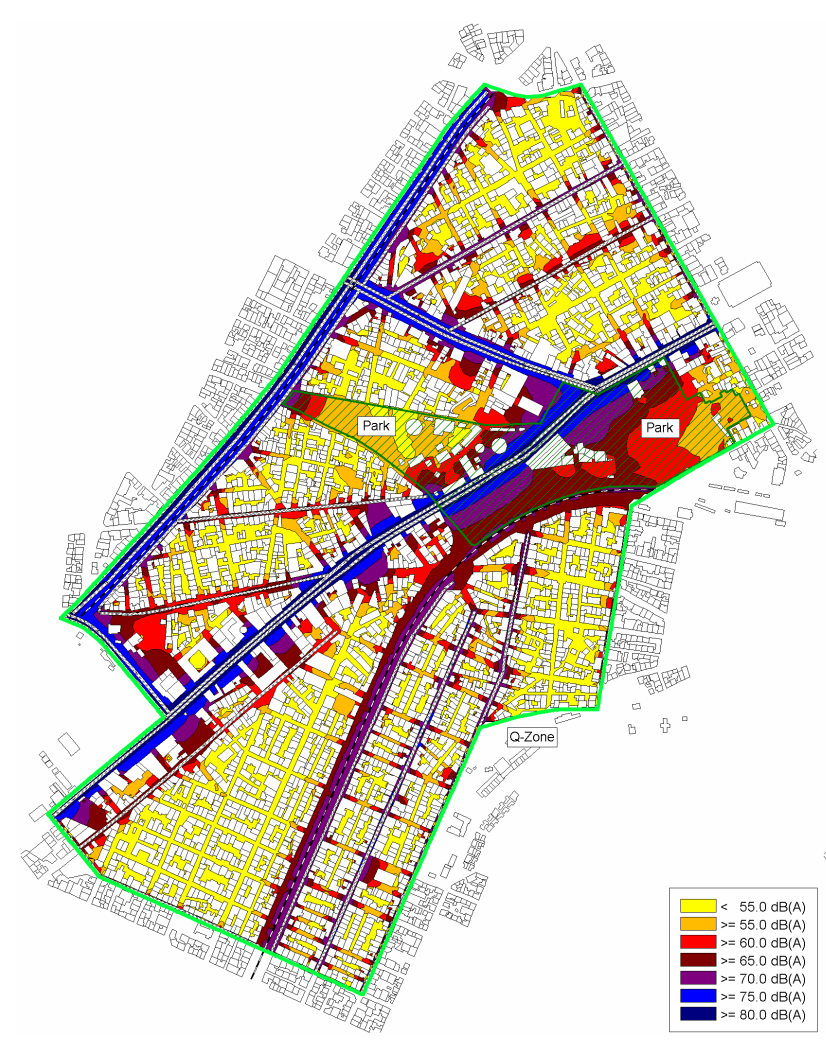

(a)

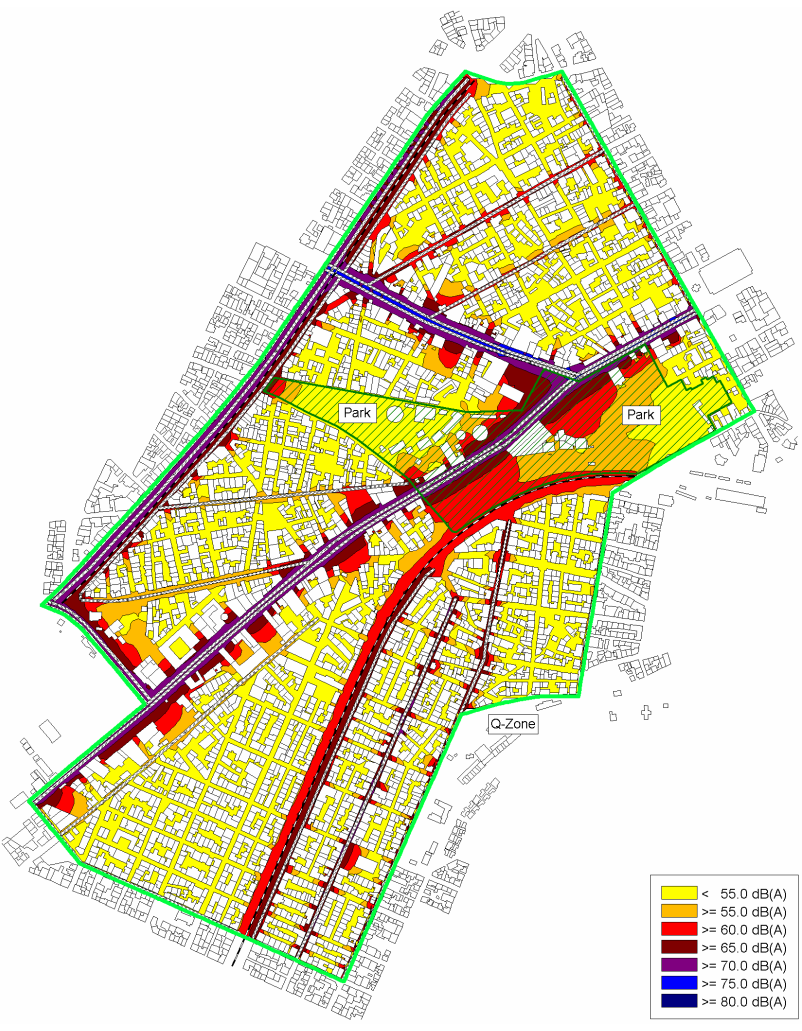

(b)

Figure 2: Noise map ( $\left.\mathrm{L}_{d e} \& L_{\text {night }}\right)$ of the Athens Q-Zone: Base case scenario S01.

left and right section, which are specified correspondingly. The other attributes refer to the estimated number of park visitors who reside in the park-surrounding and the estimated number of residents in the various park sections. The population density for the Q-Zone was used to determine the population present in the different areas, which is obtained as a function of the buildings surfaces. Values for the area of the "test site" coincides with the Q-Zone itself in this study. The Q-zone area is approximately $1 \mathrm{~km}$ by $1,5 \mathrm{~km}$. The test site is situated in the heart of the city and is affected by a major four-lane road (Piraeus Avenue) exactly in the middle, containing the major sources of noise.

The area is characterized by three parts: the large four-lane road in the center, a park already available for pedestrians in the middle of the area, and the rest of the area is made up of three- to four-storey residential building, and small one-way roads. The park is so far used mainly by young people and tourists. However, based on the questionnaires [8-11], there is as well a set of pedestrians from the local residents. Cars, powered two-wheelers (PTW) were divided into motorbikes ( $>125 \mathrm{cc}$ ) and scooters $(<125 \mathrm{cc})$, as well as heavy vehicles (trucks, busses). Therefore, four types of vehicles were modelled on the road. Two railway lines were also included in the modelling as they are on the edges of the Q-zone studied. On one side, a small railway line with trains running at low speed of typically $30 \mathrm{~km} / \mathrm{h}$; on the other side, a metro railway line with short passenger trains running at approximately $70 \mathrm{~km} / \mathrm{h}$.

The arithmetic average day/evening-time noise level $\mathrm{L}_{d e, a v}$, which is based on $10 \times 10 \mathrm{~m}^{2}$ grid calculations in the simulation software was implemented. This parameter is specified for each of the different regions that are being observed, i.e., the park and the park "surrounding", whereas the "surrounding" is defined as those residential areas that lie within reach of a five-minute walk from the park. This is assumed to be a 400-metre distance. Derived from the definition of the park "surrounding", the term "capacity" is used for the total area inside a Q-Zone embedded park, in which the average noise level $\mathrm{L}_{d e}$ is at least $10 \mathrm{~dB}$ below that of the surrounding. As a measure of annoyance in the population, the number "highly annoyed people (HAP)" was used. This is a single-number value referring to the number of inhabitants that are severely troubled by the noise. Depending on the context, the number of HAP can be related to a building, the Q-zone, or the test site. The HAP parameter and the parameter $\mathrm{L}_{D E N}$ ' on which 


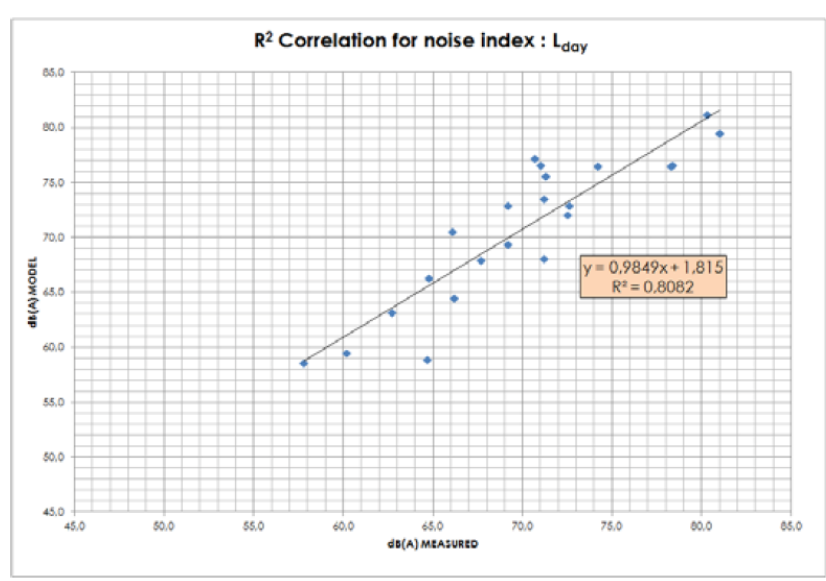

Figure 3: $\mathrm{R}^{2}$ Correlation for noise index: $\mathrm{L}_{\text {day }}$.

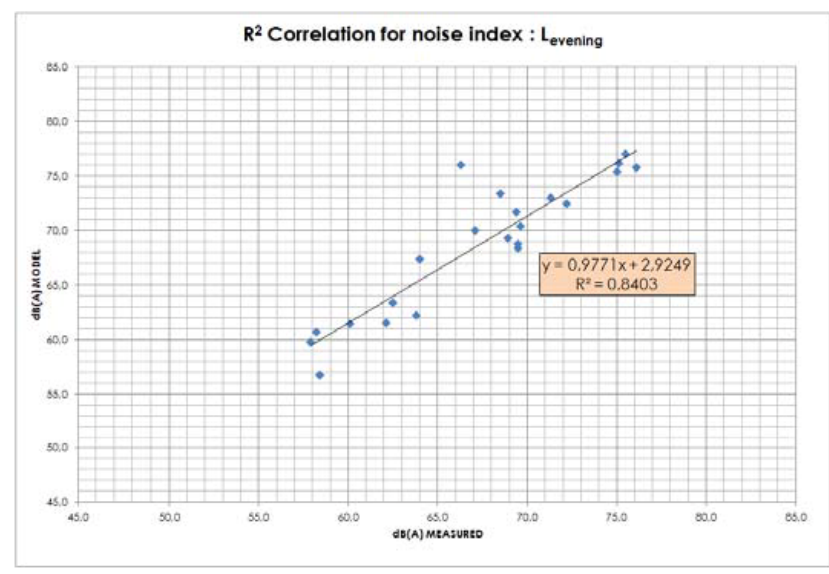

Figure 4: $R^{2}$ Correlation for noise index: $L_{\text {evening }}$.

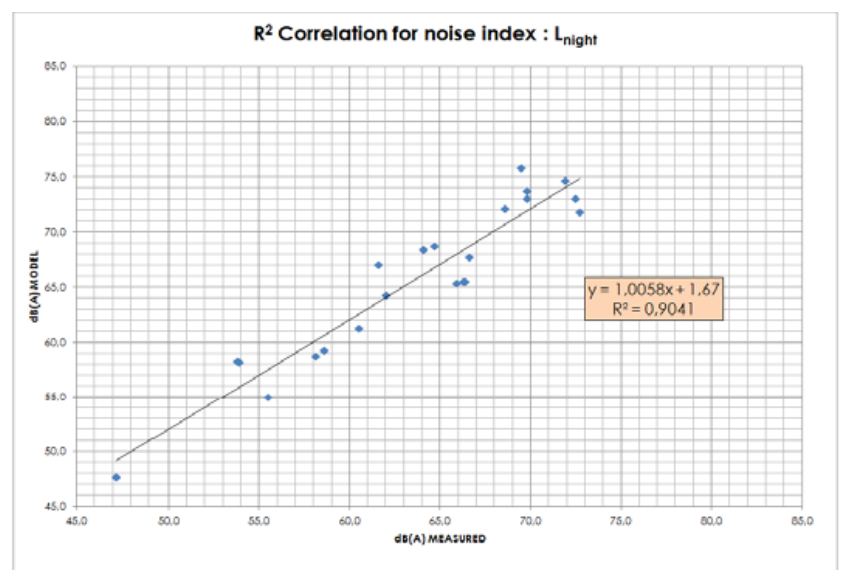

Figure 5: $R^{2}$ Correlation for noise index: $L_{\text {night }}$.

the HAP is based on are described in "Refined noise score rating model for residents" [12].

The noise descriptor "number of annoyed park visitors" was also used, based a noise score rating model for visitors of parks that was developed in the CityHush project under "noise score rating models and annoyance, preliminary noise score rating model for the outdoors" [13]. The indicators here for outdoor noise were combined with functional information of the area, as well as the number of people making use of the area. This was used to predict the overall annoyance response, which implies the percentage and the absolute amount of visitors that are expected to be annoyed in a defined area. A costbenefit analysis (CBA) provides the means to systematically compare the value of outcomes with the value of resources achieving the outcomes required. It measures the economic efficiency of the proposed approach. When all else being equal, more efficient approaches should be chosen over less efficient ones. When there are many options to consider during a decision-making task, it is useful to evaluate the options with a common metric. A cost-benefit analysis refers to any type of structured method for evaluating decision options. The calculation of noise costs was based on the noise distribution calculated as the total area affected by noise within a range of a given $1 \mathrm{~dB}$ class [14].

\section{Environmental noise map}

Figure 2 shows a noise map of the test site. The map was obtained by assuming that reflective ground and buildings are present, vehicles running at constant speed, and by including the few major roads in the model, while neglecting all other roads. Road traffic on the two major roads, the one running through the park, and the one to its north and west are the two major sources of noise. The railway line to the south of the park is also a major noise source, although not with as high values as the aforementioned roads. Two railway lines were modelled as well, one at the north-west of the map and one at the south, crossing the embedded park and all included in the Q-zone. This second railway line is also a major noise source, although not with as high noise contribution as the major roads. In this map, the distribution of levels $\mathrm{L}_{d e, a v}$ are illustrated by an overlaid colour grid. The noise distribution in Figure 2 reflects the original (current) situation on the test site, which constitutes the base case. The railway line to the south of the park is also a major noise source although not with as high values as the aforementioned roads.

A statistical comparative analysis in 22 distinct locations, within the test area, was executed, based on both predicted average noise data from the noise model, and the measured data for all noise indices, i.e. $\mathrm{L}_{d a y} \mathrm{~L}_{\text {evening }}$ and $\mathrm{L}_{\text {night }}$. An excellent correlation coefficient $\mathrm{R}^{2}$ was proven 
Table 2: Q-Zone scenario configurations in Athens test site.

\begin{tabular}{|c|c|c|}
\hline Scenario & Description & Details \\
\hline S01 & $\begin{array}{l}\text { Status Quo traffic composition (cars, truck } \\
\text { scooters, motorbikes) and real background noise } \\
\text { caused by rail - Base case }\end{array}$ & \\
\hline S02 & $\begin{array}{l}\text { S01 + speed reduction at Piraeus Avenue (main } \\
\text { road through the Q-Zone and park) + 50\% electric } \\
\text { scooters and motorbikes within the fleet at all road } \\
\text { sections within the Q-Zone }\end{array}$ & $\begin{array}{c}20 \mathrm{~km} / \mathrm{h} \text { speed reduction at Piraeus Avenue; } 50 \% \\
\text { reduction of number of scooters }(<125 \mathrm{cc}) \text { and } \\
\text { motorbikes }(>125 \mathrm{cc})\end{array}$ \\
\hline S03 & $\mathrm{S} 02+5 \mathrm{~dB}$ reduction of background noise from rail & \\
\hline S04 & $\begin{array}{c}\text { S01 + speed reduction at Piräus Avenue (main road } \\
\text { through the Q-Zone and park) }+100 \% \text { electric } \\
\text { scooters and motorbikes within the fleet at all road } \\
\text { sections within the Q-Zone }\end{array}$ & $\begin{array}{l}20 \mathrm{~km} / \mathrm{h} \text { speed reduction at Piraeus Avenue; } 100 \% \\
\text { reduction of number of conventional scooters } \\
(<125 \mathrm{cc}) \text { and motorbikes }(>125 \mathrm{cc}) \rightarrow \text { No } \\
\text { conventional scooters and no motor bikes }\end{array}$ \\
\hline S05 & S04 $+5 \mathrm{~dB}$ reduction of background noise from rail & \\
\hline S06 & $\begin{array}{c}\text { S04 }+20 \% \text { electric cars ( } 20 \% \text { electric cars and } \\
\text { buses and only electric PTW in the Q-zone and } \\
\text { speed reduction) }\end{array}$ & $\begin{array}{l}20 \mathrm{~km} / \mathrm{h} \text { speed reduction at Piraeus Avenue; } 100 \% \\
\text { reduction of number of conventional scooters } \\
(<125 \mathrm{cc}) \text { and motorbikes }(>125 \mathrm{cc}) \rightarrow \text { No } \\
\text { conventional scooters and no motor bikes; } 20 \% \\
\text { reduction of number of conventional cars }\end{array}$ \\
\hline S07 & $\mathrm{S} 06+5 \mathrm{~dB}$ reduction of background noise from rail & \\
\hline
\end{tabular}

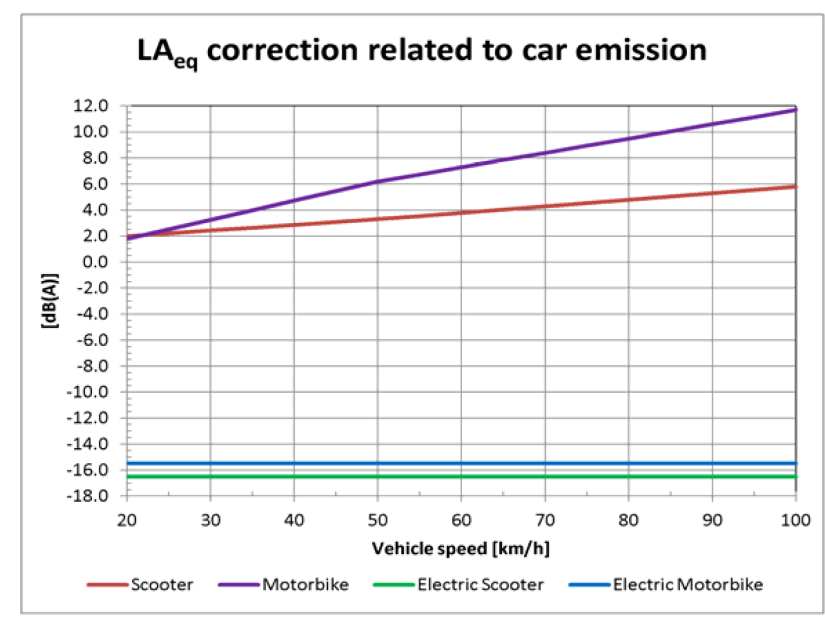

Figure 6: $\mathrm{L}_{A e q}$ correction for PTWs as a function of speed.

ensuring the accuracy of the acoustic model of the test site (see relevant diagrams in Figures 3, 4, 5).

\section{Trafic noise map scenarios}

In Table 2, the various noise maps scenarios configurations applied to the Athens test site are compiled. Scenario S01 describes the base case scenario, i.e., the situation as it is currently found in Athens. The other scenarios describe the introduction of various limitations, such as speed limits on certain road links and various configurations in the traffic mix, (i.e., the proportion of low noise vehicles (LNV) in the population). For the test site in Athens, the focus lies particularly in investigating the noise effects by changing the mix of the powered two-wheeler (PTW) fleet. For this, it is assumed that a certain percentage of the current scooter and motorbike fleet are to be replaced by electric scooters and electric motorbikes. Additionally, the effects of increasing the proportion of electric cars and reducing the railway noise by $5 \mathrm{~dB}$ are also simulated.

The given scenarios do not include an analysis of the effects of shifts in the traffic along the roads external to the Q-zone. Traffic speeds used in the model (i.e., $70 \mathrm{~km} / \mathrm{h}$ ) are not representative of the real site. Therefore, two speed sets were used namely $70 \mathrm{~km} / \mathrm{h}$ and $50 \mathrm{~km} / \mathrm{h}$. In reality, the speeds measured on the site were between $30 \mathrm{~km} / \mathrm{h}$ and $50 \mathrm{~km} / \mathrm{h}$, and only very exceptionally reaching $70 \mathrm{~km} / \mathrm{h}$. In order to perform noise forecasts for PTW, the noise emissions $\left(\mathrm{L}_{A e q}\right)$ of this vehicle class had to be determined. The noise emissions for four different types of PTWs were derived from known $\mathrm{L}_{A e q}$ values for cars as a function of speed. This function is referred to as the " $\mathrm{L}_{A e q}$ correction related to car emissions". The different PTW types are conventional scooters and motorbikes as well as electric scooters and motorbikes. The corresponding correction func- 
Table 3: $\mathrm{L}_{\text {Aeq }}$ correction related to car emissions for various PTWs for discrete speeds in $5 \mathrm{~dB}$ steps in the range of $20 \mathrm{~km} / \mathrm{h}$ to $100 \mathrm{~km} / \mathrm{h}$.

\begin{tabular}{llccccccccc}
\hline Vehicle speed & {$[\mathrm{km} / \mathrm{h}]$} & 20 & 25 & 30 & 35 & 40 & 45 & 50 & 55 & 60 \\
Scooter & {$[\mathrm{dB}(\mathrm{A})]$} & 2.0 & 2.2 & 2.4 & 2.7 & 2.9 & 3.1 & 3.3 & 3.6 & 3.8 \\
Motorbike & {$[\mathrm{dB}(\mathrm{A})]$} & 1.8 & 2.5 & 3.3 & 4.0 & 4.7 & 5.5 & 6.2 & 6.8 & 7.3 \\
Electric Scooter & {$[\mathrm{dB}(\mathrm{A})]$} & -16.5 & -16.5 & -16.5 & -16.5 & -16.5 & -16.5 & -16.5 & -16.5 & -16.5 \\
Electric Motorbike & {$[\mathrm{dB}(\mathrm{A})]$} & -15.5 & -15.5 & -15.5 & -15.5 & -15.5 & -15.5 & -15.5 & -15.5 & -15.5 \\
\hline Vehicle speed & {$[\mathrm{km} / \mathrm{h}]$} & 65 & 70 & 75 & 80 & 85 & 90 & 95 & 100 & \\
Scooter & {$[\mathrm{dB}(\mathrm{A})]$} & 4.1 & 4.3 & 4.6 & 4.8 & 5.1 & 5.3 & 5.6 & 5.8 & \\
Motorbike & {$[\mathrm{dB}(\mathrm{A})]$} & 7.9 & 8.4 & 9.0 & 9.5 & 10.1 & 10.6 & 11.2 & 11.7 & \\
Electric Scooter & {$[\mathrm{dB}(\mathrm{A})]$} & -16.5 & -16.5 & -16.5 & -16.5 & -16.5 & -16.5 & -16.5 & -16.5 & \\
Electric Motorbike & {$[\mathrm{dB}(\mathrm{A})]$} & -15.5 & -15.5 & -15.5 & -15.5 & -15.5 & -15.5 & -15.5 & -15.5 & \\
\hline
\end{tabular}

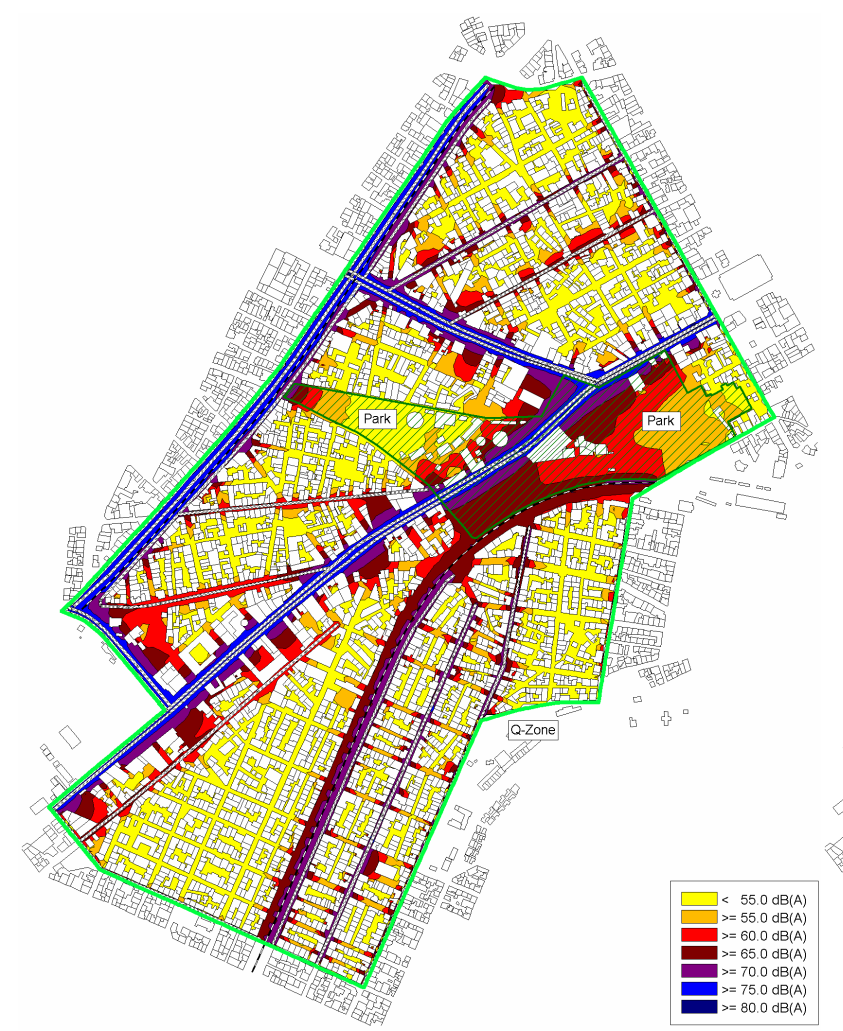

(a)

Figure 7: Scenario S02 - $\mathrm{L}_{d e} \& \mathrm{~L}_{\text {night }}$.

tions are shown in Figure 6 and the tabulated values are shown in Table 3.

\section{The noise situation for all traffic scenarios}

The results for the various scenarios ( $\mathrm{S} 02$ to $\mathrm{S} 07$ ) in terms of their impact on the park and the Q-Zone are shown in

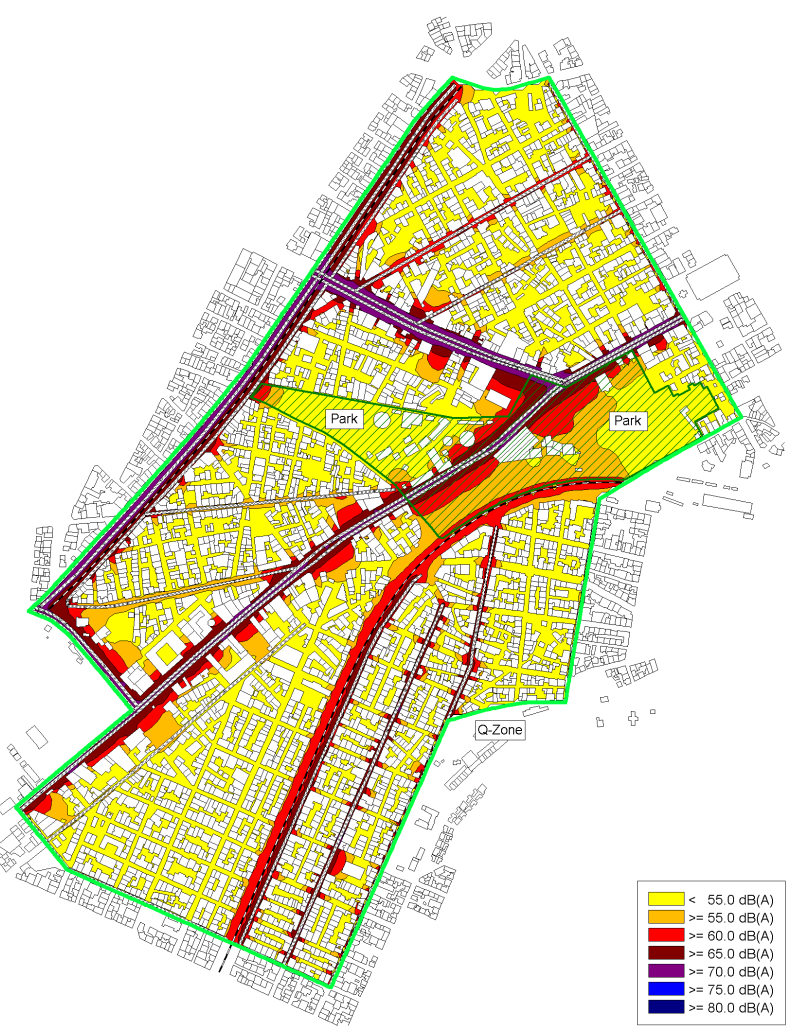

(b)

the Figures 7 to 12 hereafter using CadnaA software [15]. The effects on the average noise levels of the different QZone traffic scenarios were evaluated by studying the noise levels and their distribution on the relevant noise map, as well as by studying the differences compared to the base case scenario on noise difference maps computed and presented in Figures 13 to 18. 


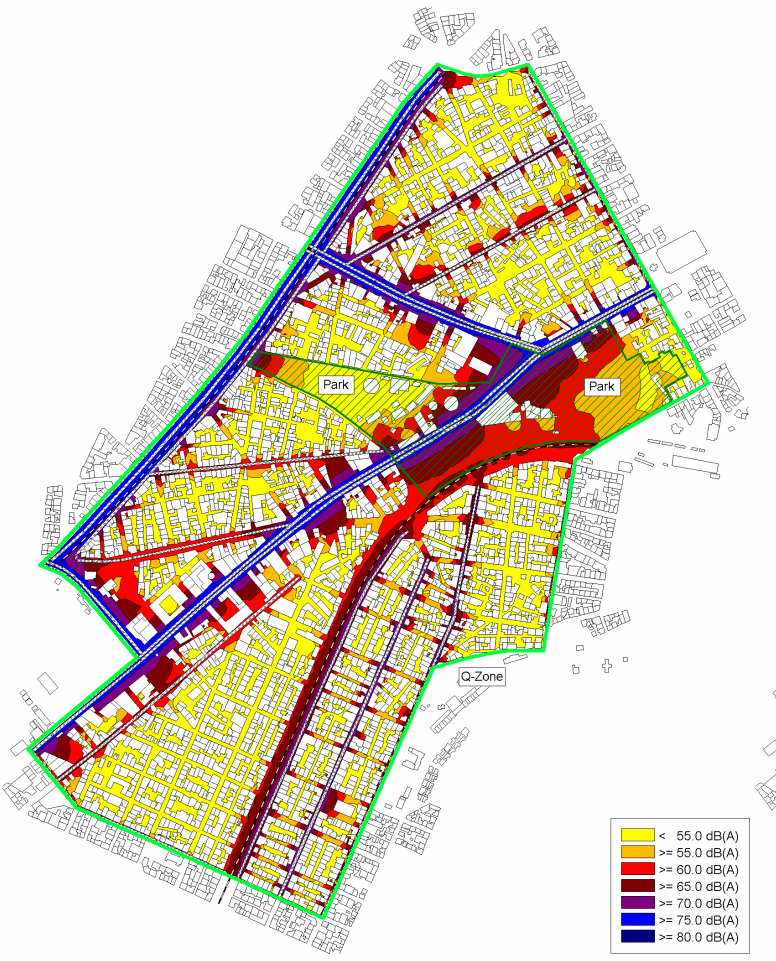

(a)

Figure 8: Scenario $\mathrm{S} 03-\mathrm{L}_{\text {de }}$ \& $\mathrm{L}_{\text {night }}$.

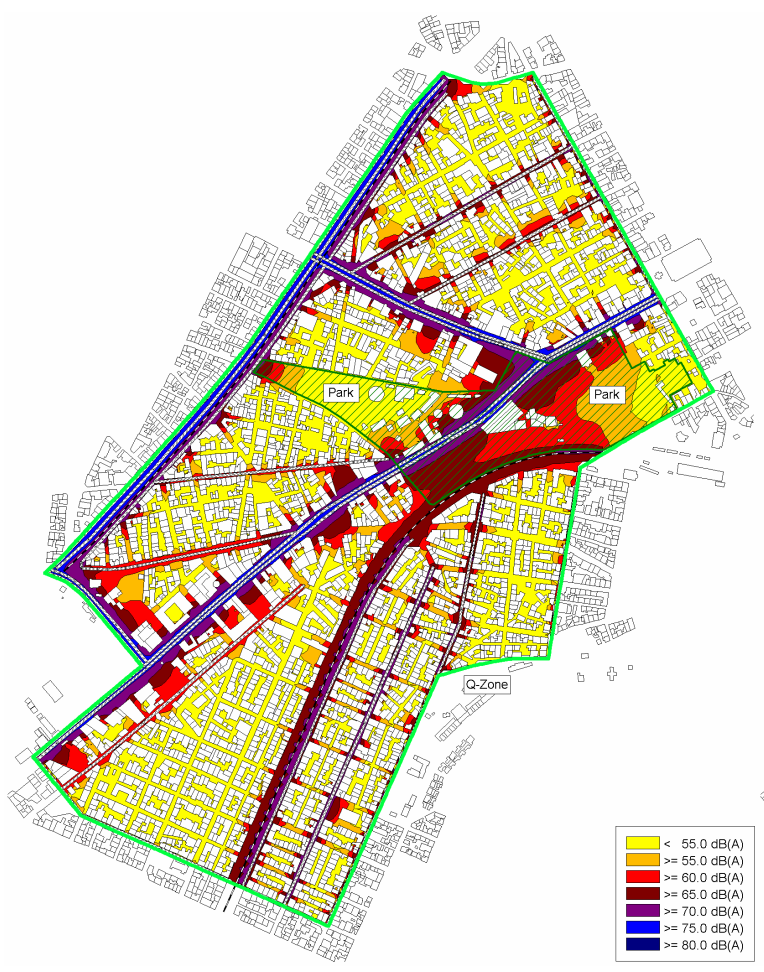

(a)

Figure 9: Scenario S04 - $\mathrm{L}_{d e}$ \& $\mathrm{L}_{\text {night }}$.

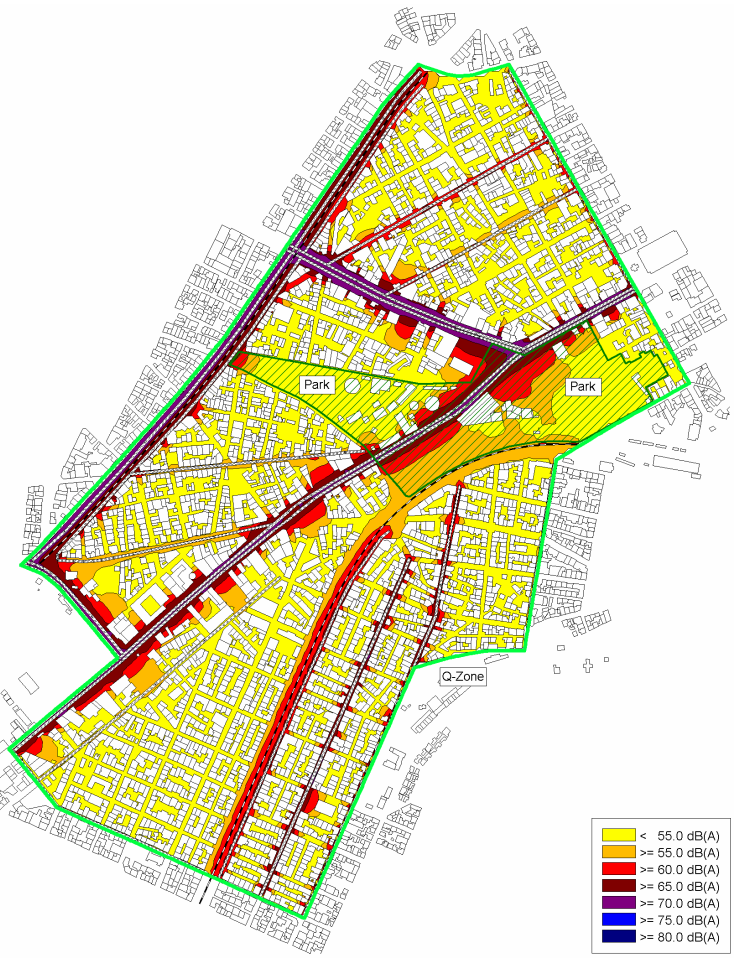

(b) 


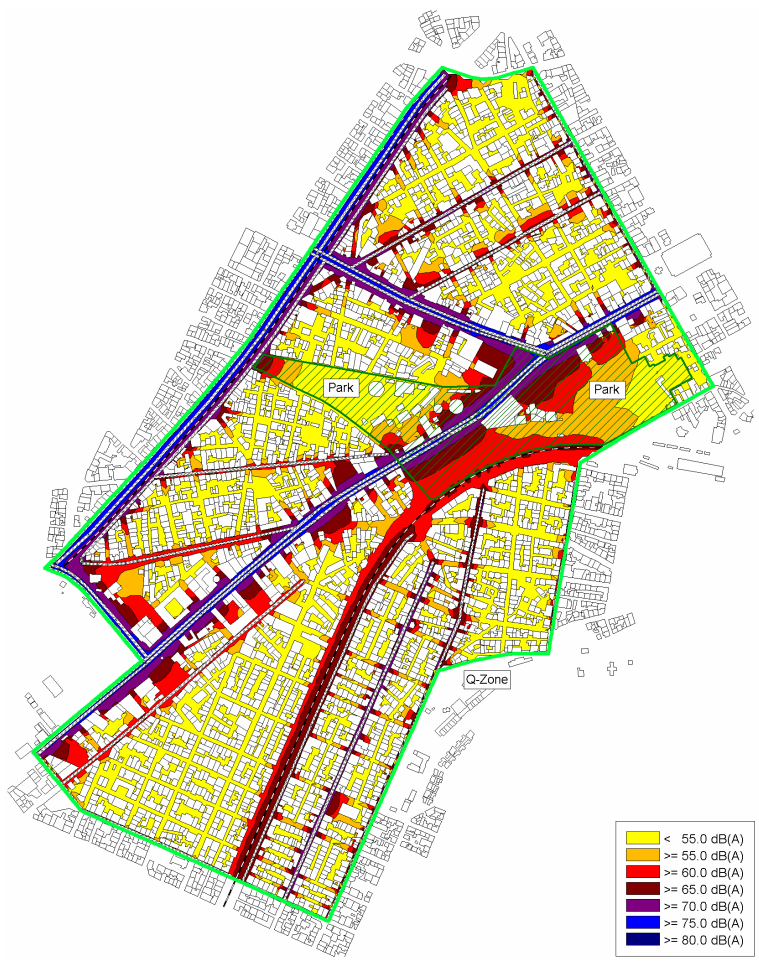

(a)

Figure 10: Scenario S05 - $\mathrm{L}_{d e} \& \mathrm{~L}_{\text {night }}$.

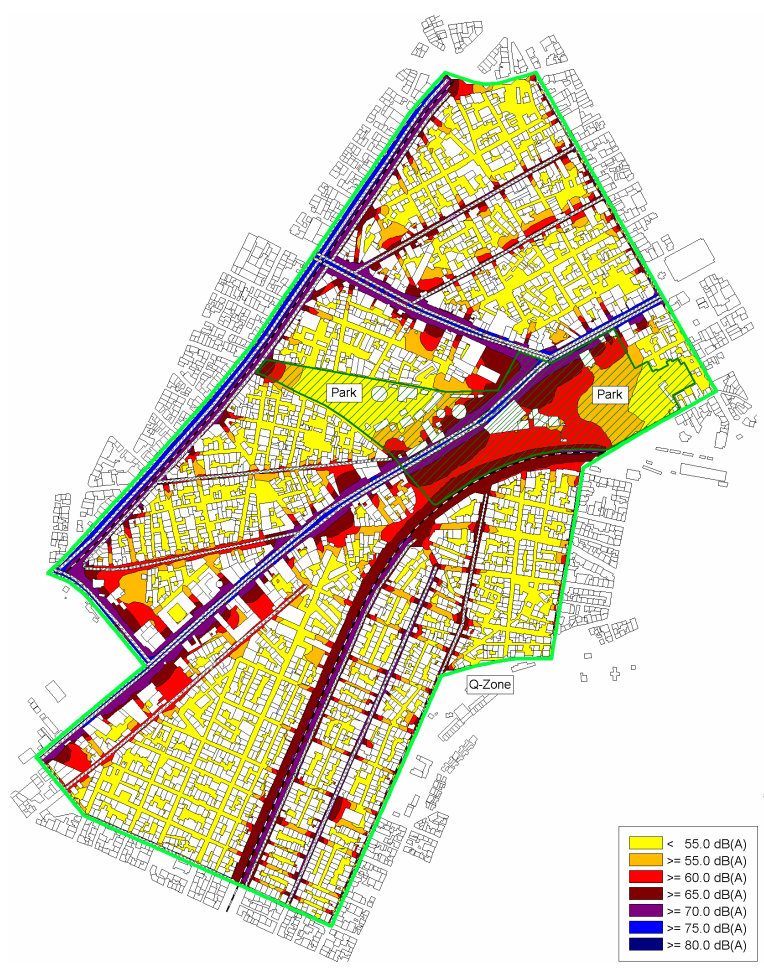

(a)

Figure 11: Scenario S06 - $\mathrm{L}_{d e} \& \mathrm{~L}_{\text {night }}$.

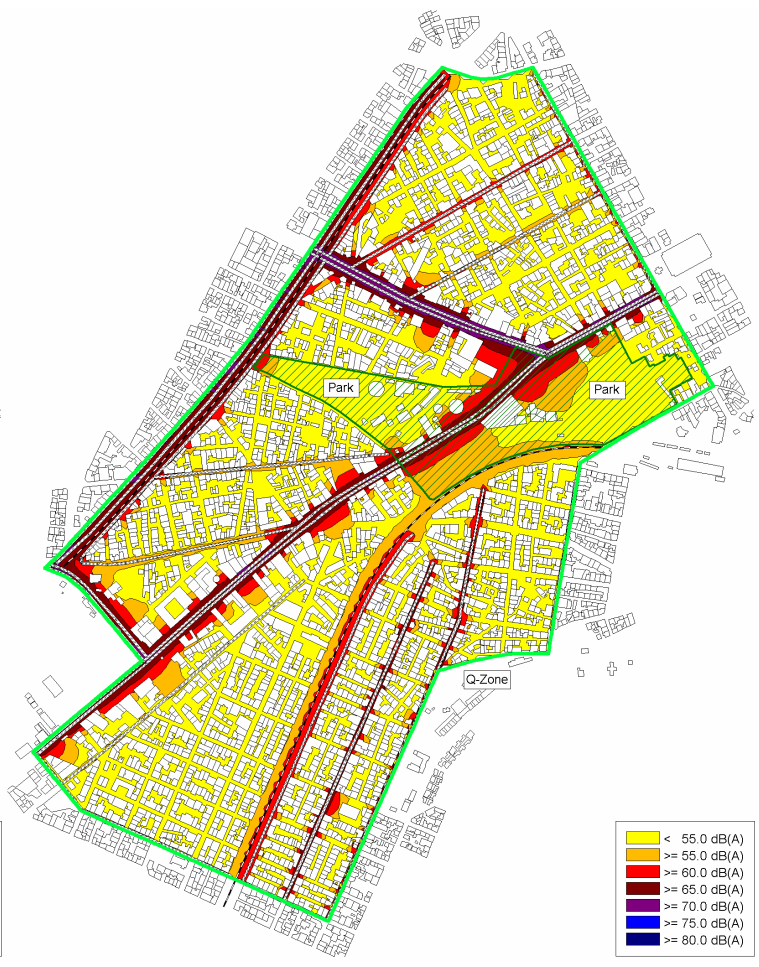

(b) 


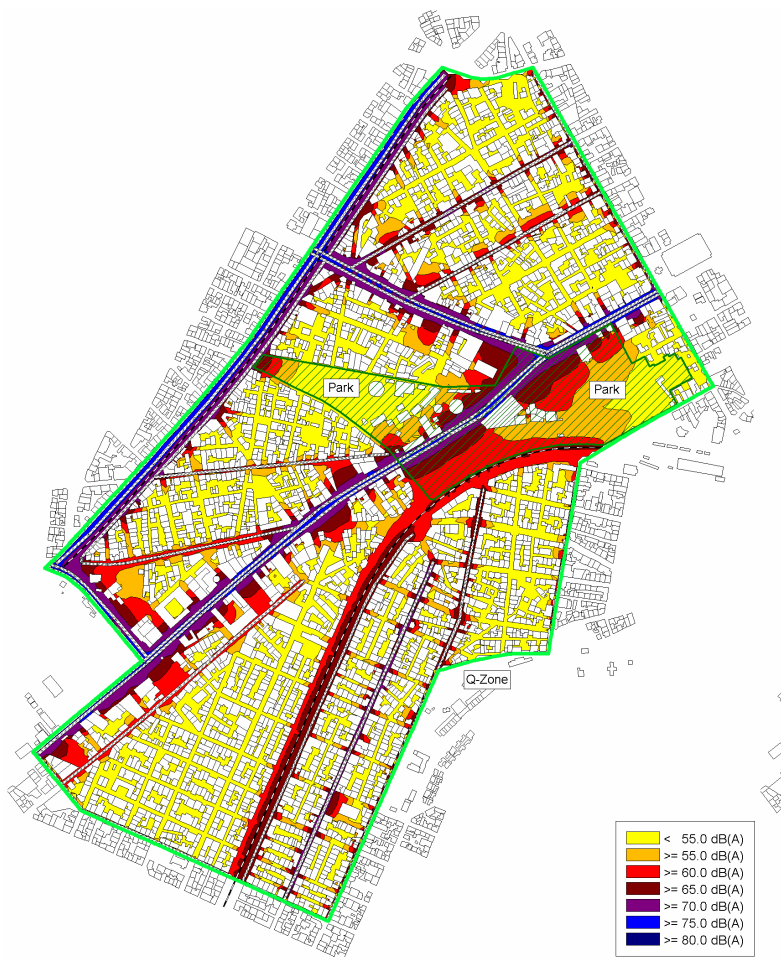

(a)

Figure 12: Scenario S07 - $\mathrm{L}_{d e} \& \mathrm{~L}_{\text {night }}$.

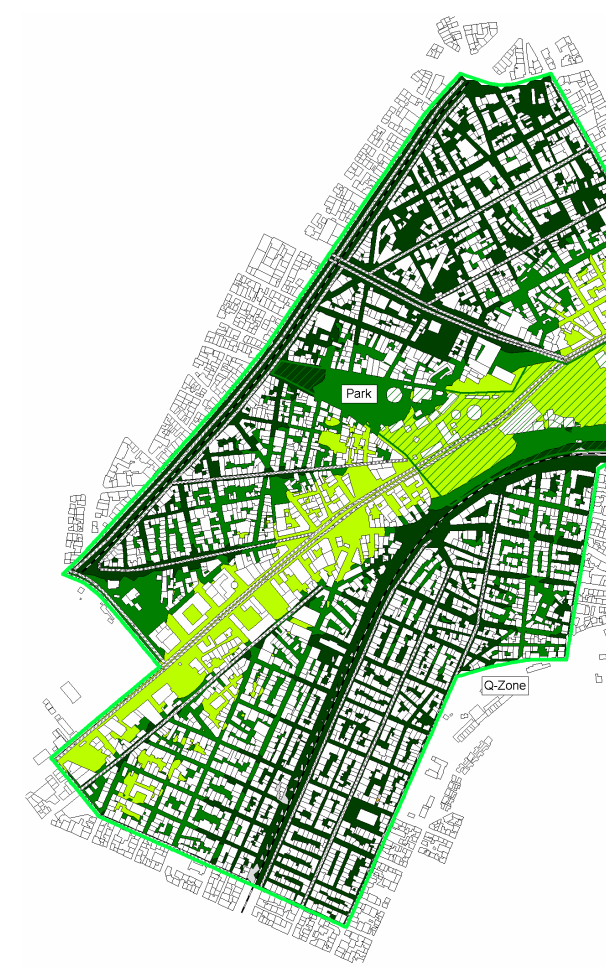

(a)

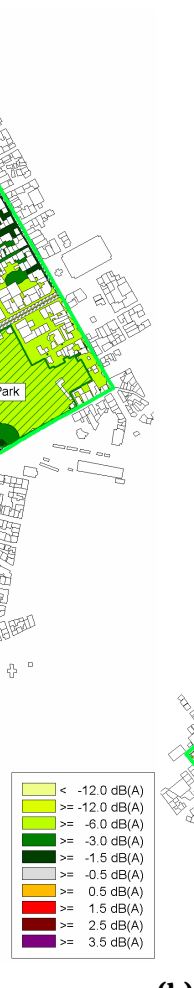

(b)

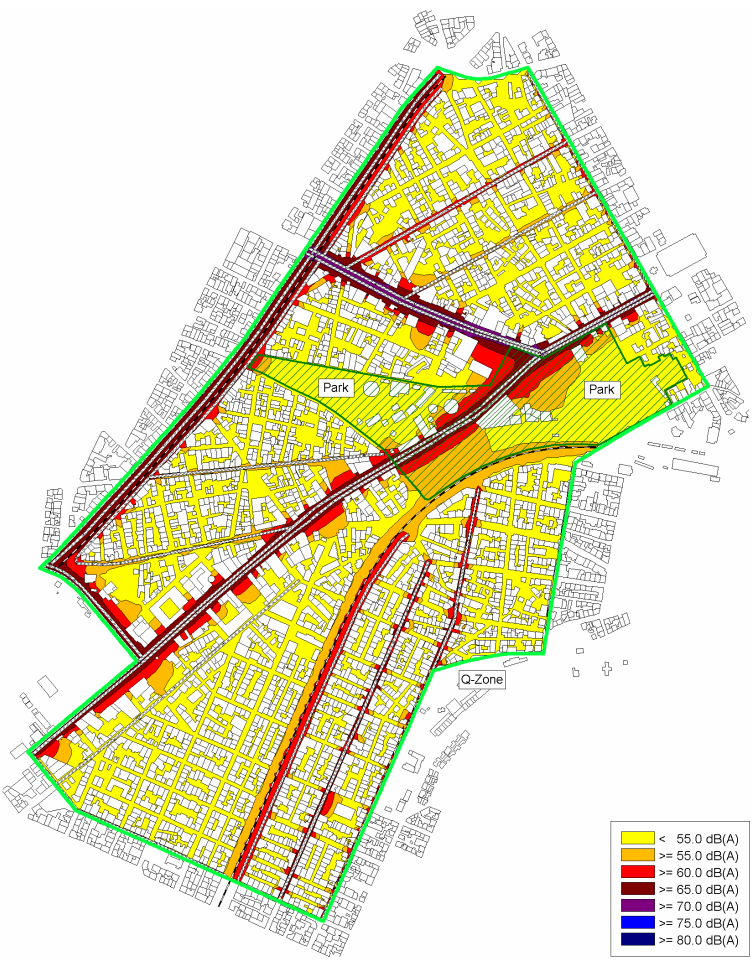

(b)

Figure 13: Difference Scenarios S02-S01 - $\mathrm{L}_{d e}$ \& $\mathrm{L}_{\text {night }}$. 


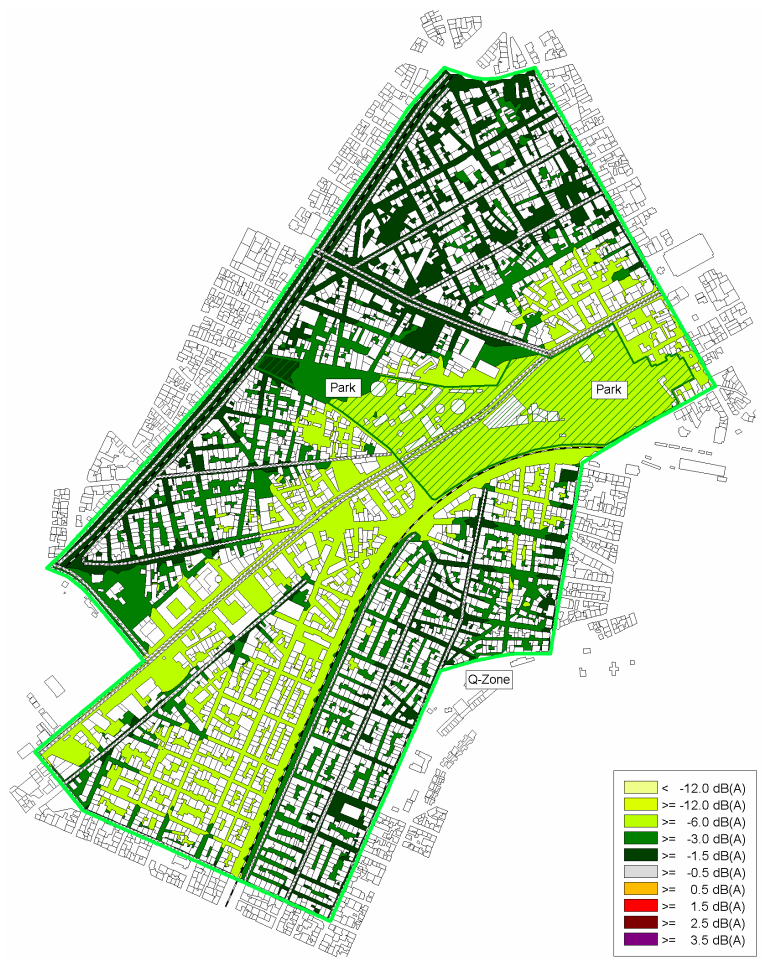

(a)

Figure 14: Difference Scenarios (S03-S01 - $\mathrm{L}_{d e}$ \& $\mathrm{L}_{\text {night }}$.

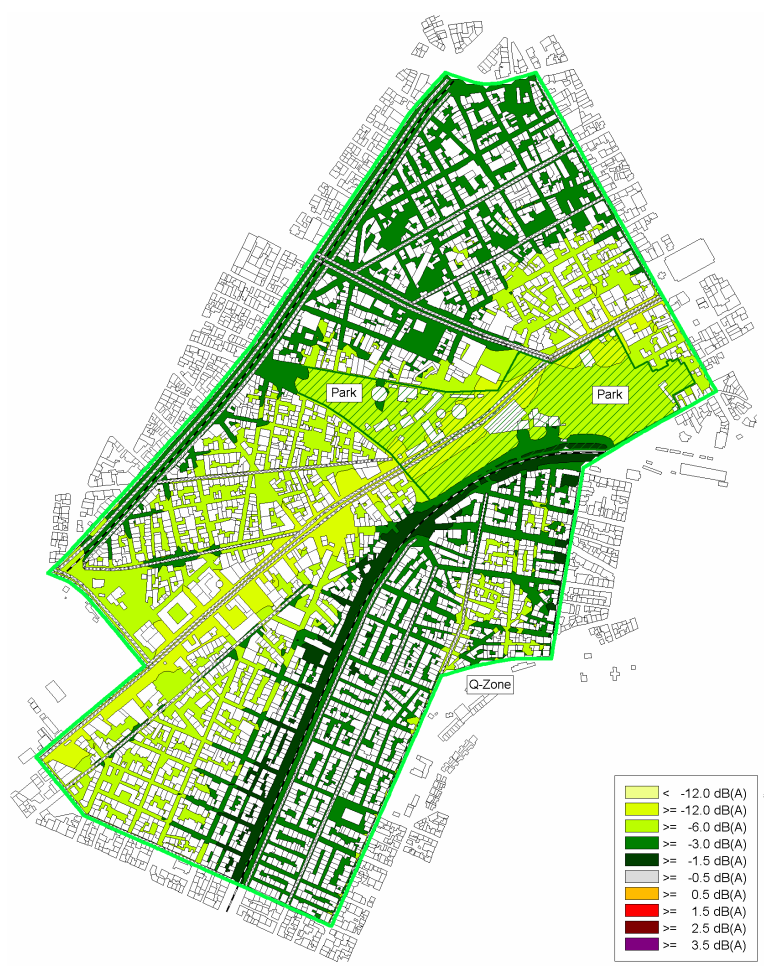

(a)

Figure 15: Difference Scenarios S04-S01 - $\mathrm{L}_{d e} \& \mathrm{~L}_{\text {night }}$.

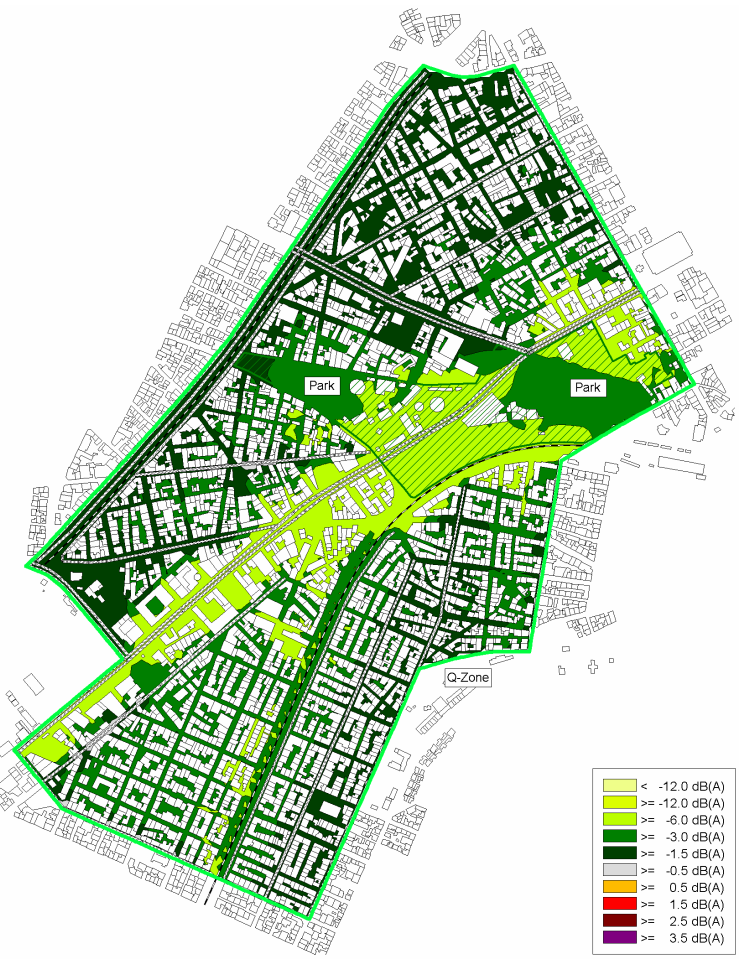

(b) 


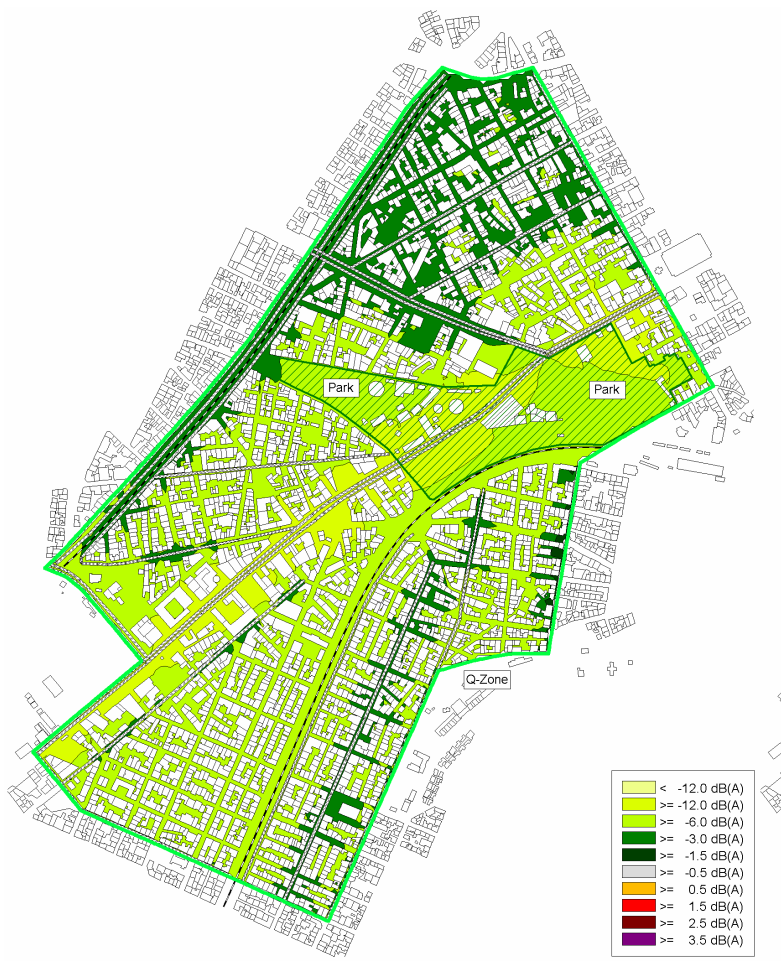

(a)

Figure 16: Difference Scenarios S05-S01- $\mathrm{L}_{d e}$ \& $\mathrm{L}_{\text {night }}$.

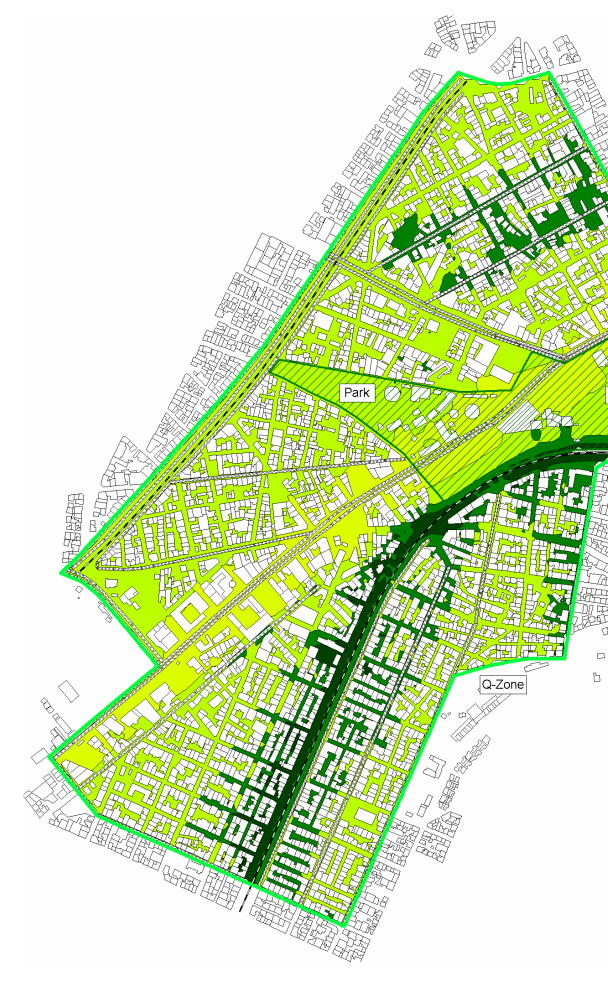

(a)

)

Figure 17: Difference Scenarios S06-S01 - $\mathrm{L}_{d e}$ \& $\mathrm{L}_{\text {night }}$.

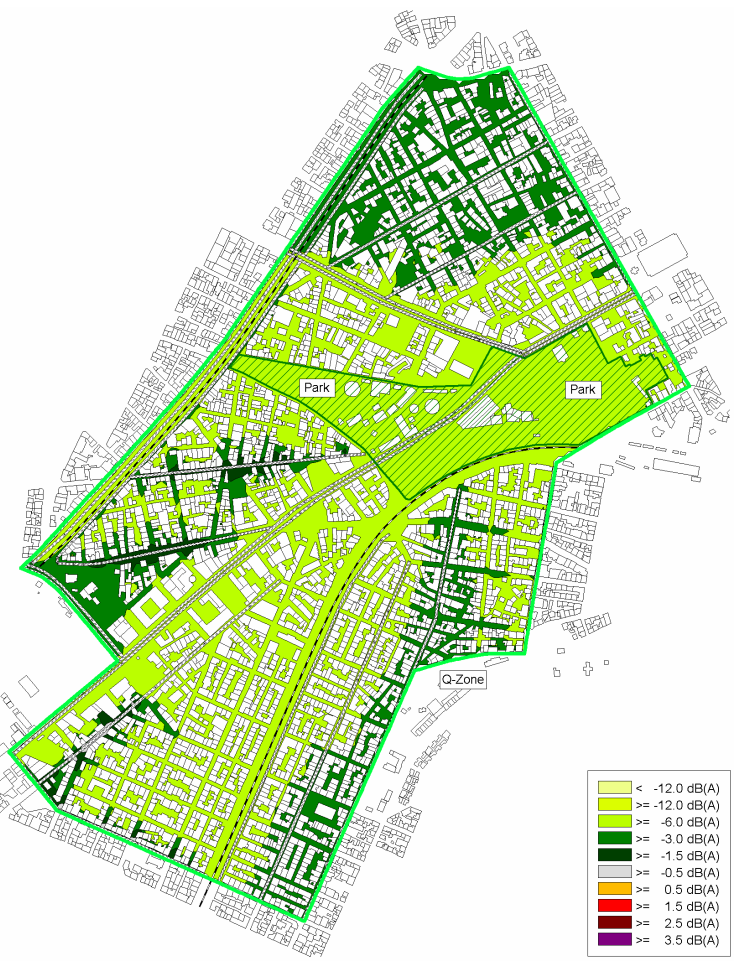

(b) 


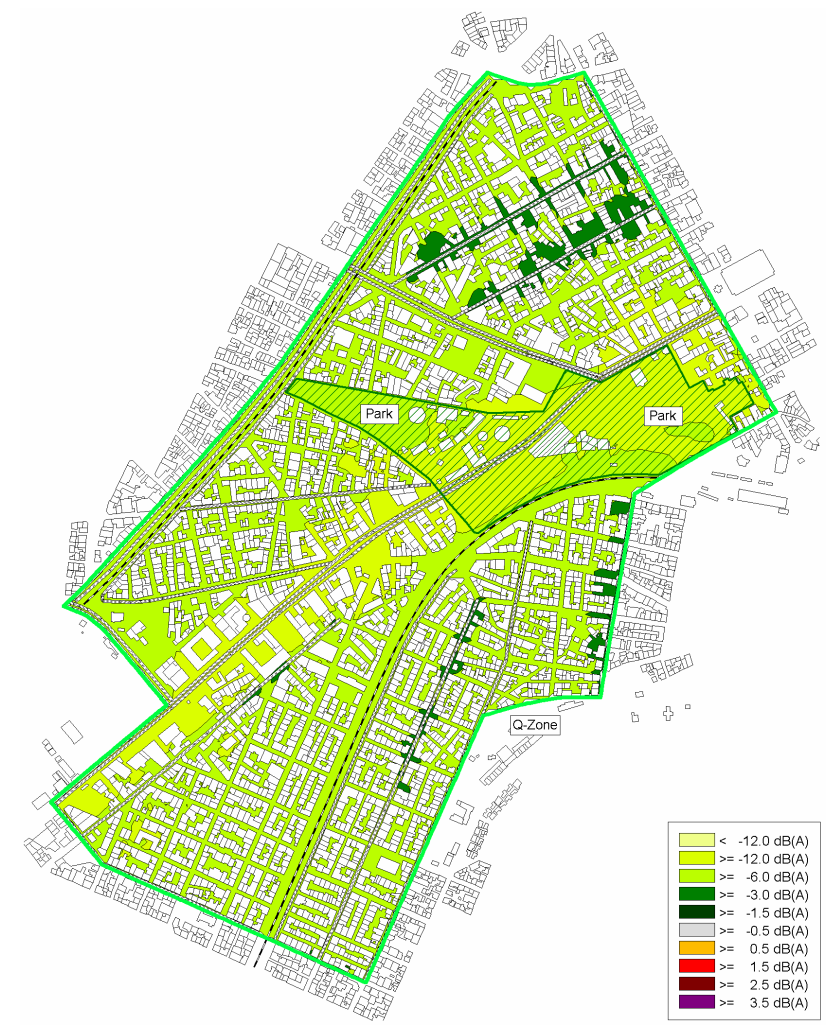

(a)

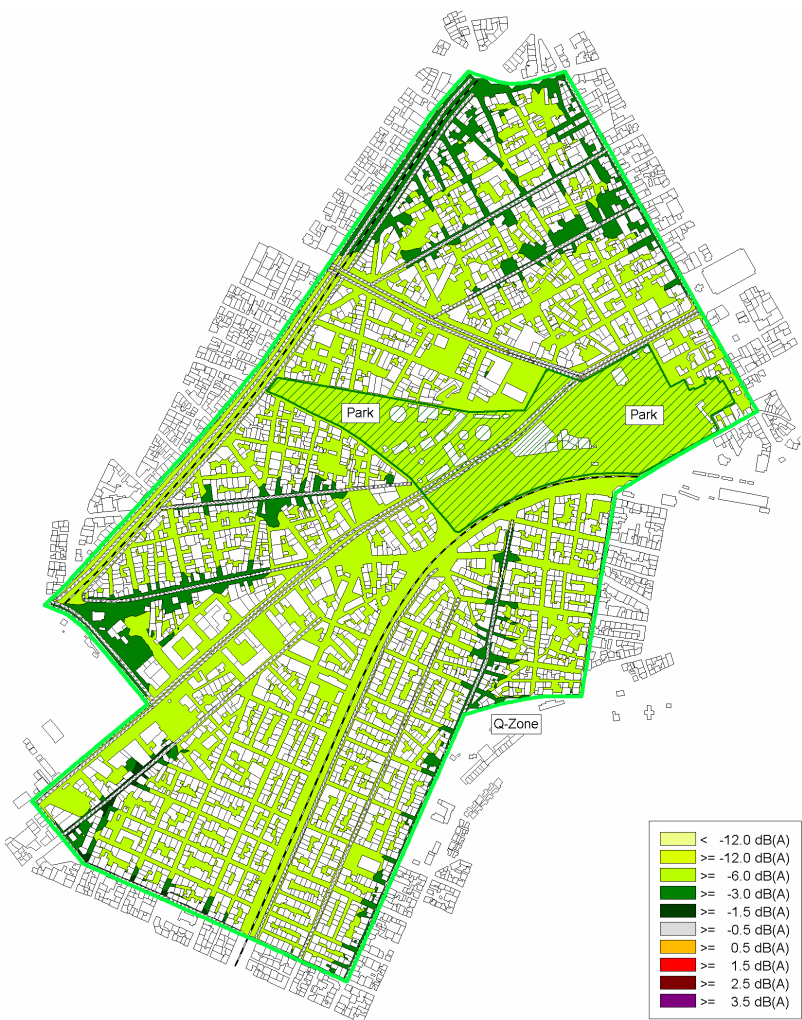

(b)

Figure 18: Difference Scenarios S07-S01 - $\mathrm{L}_{d e} \& \mathrm{~L}_{\text {night }}$.

Table 4: Q-Zone $\mathrm{L}_{d e, a v}$ average values for each of the scenarios, the number of residents and the number of HAP in the Q-Zone.

\begin{tabular}{lccccccc}
\hline Scenarios & S01 & S02 & S03 & S04 & S05 & S06 & S07 \\
\hline $\mathrm{L}_{d e, a v}[\mathrm{~dB}(\mathrm{~A})]$ & 60.3 & 58.4 & 57.9 & 57.0 & 56.3 & 56.4 & 55.7 \\
No. residents \# & 19547 & 19547 & 19547 & 19547 & 19547 & 19547 & 19547 \\
HAP\# & 1599 & 1414 & 1348 & 1263 & 1188 & 1192 & 1113 \\
\hline
\end{tabular}

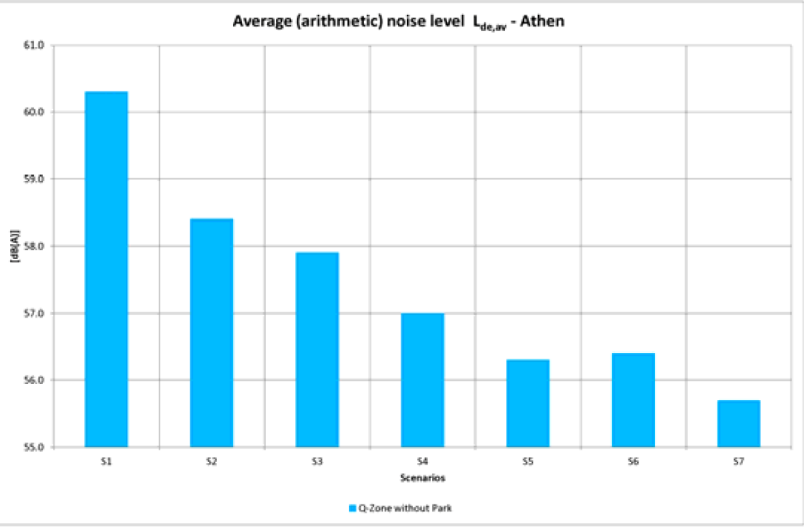

Figure 19: Average (arithmetic) noise level $\mathrm{L}_{d e, a v}$ in the Athens QZone calculated without the park area.

\section{Results}

In Figure 19, the arithmetically averaged noise levels $\mathrm{L}_{d e, a v}$ in the Q-Zone are shown. The area of the park is excluded from this analysis. A decline in average noise levels can be observed, starting at $60.3 \mathrm{~dB}(\mathrm{~A})$ in scenario $\mathrm{S} 01$ and reaching a minimum of $55.7 \mathrm{~dB}(\mathrm{~A})$ in scenario S07. This is an improvement of $4.6 \mathrm{~dB}$ from scenario S01 to S07. In Table 4, the absolute values for each scenario together with the number of residents in the Q-Zone and the number of HAP are given.

In Figure 20, the average noise levels $\mathrm{L}_{d e, a v}$ for the complete park are shown with the capacity values for each scenario. The trend of decreasing average noise levels in the park throughout the different scenarios is the same as 
Table 5: $\mathrm{L}_{d e, a v}$ average values in the park (complete) and the park surrounding specified for each of the scenarios. The corresponding capacity values are also given.

\begin{tabular}{lccccccc}
\hline Scenarios & S01 & S02 & S03 & S04 & S05 & S06 & S07 \\
\hline $\mathrm{L}_{d e, a v}[\mathrm{~dB}(\mathrm{~A})]$ (park complete) & 66.5 & 63.2 & 62.5 & 61.8 & 60.9 & 61.3 & 60.3 \\
$\mathrm{~L}_{d e, a v}[\mathrm{~dB}(\mathrm{~A})]$ (surrounding) & 60.8 & 58.9 & 58.4 & 57.5 & 56.9 & 56.9 & 56.3 \\
“Capacity” $\left[\mathrm{m}^{2}\right]$ of park complete & 254 & 761 & 1904 & 3046 & 10025 & 5837 & 12817 \\
\hline
\end{tabular}

Table 6: $\mathrm{L}_{d e, a v}$ average values for all scenarios.

\begin{tabular}{lccccccc}
\hline Scenarios & S01 & S02 & S03 & S04 & S05 & S06 & S07 \\
\hline $\mathrm{L}_{d e, a v}[\mathrm{~dB}(\mathrm{~A})]$ (park left) & 64.3 & 61.1 & 60.7 & 59.6 & 59.0 & 59.1 & 58.4 \\
$\mathrm{~L}_{d e, a v}[\mathrm{~dB}(\mathrm{~A})]$ (surrounding) & 60.8 & 58.9 & 58.4 & 57.5 & 56.9 & 56.9 & 56.3 \\
"Capacity” [m²] of park left & 0 & 479 & 1581 & 2682 & 9580 & 5509 & 12023 \\
\hline
\end{tabular}

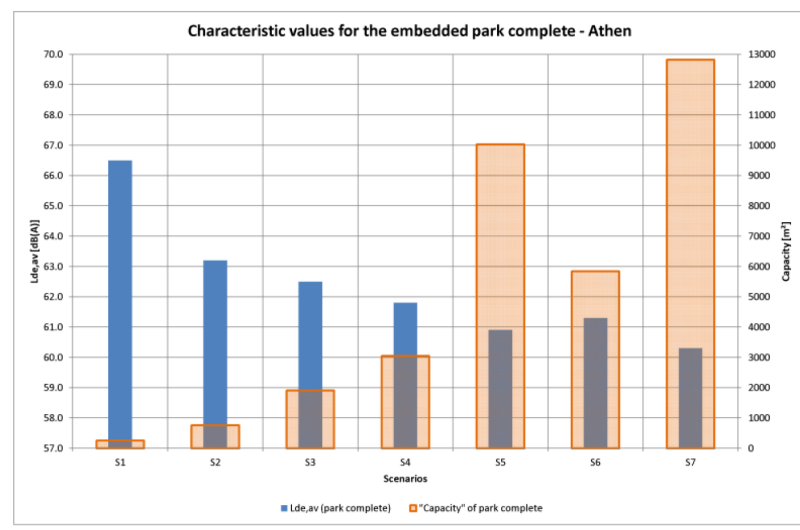

Figure 20: Average (arithmetic) noise level $\mathrm{L}_{d e, a v}$ and the capacity of the complete park in Athens in the various scenario configurations.

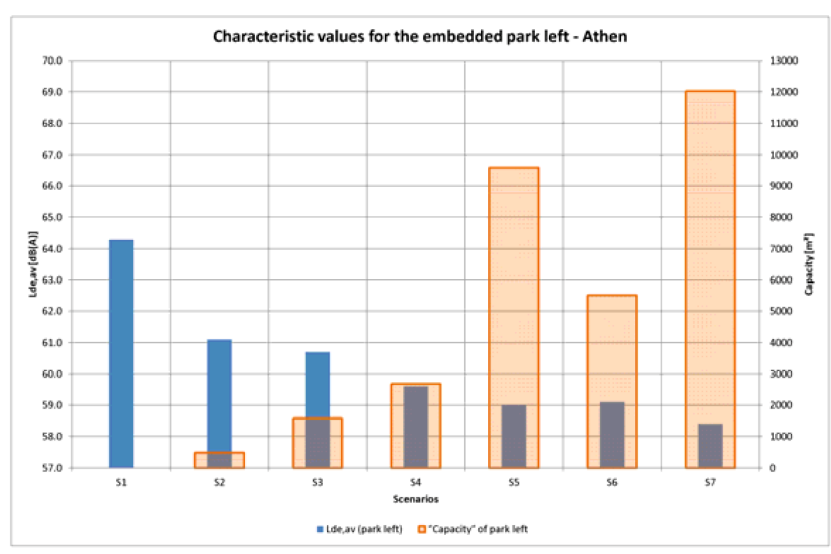

Figure 21: Average (arithmetic) noise levels $L_{d e, a v}$ and the capacity of the left hand side of the park in Athens in the various scenario configurations.

for the Q-Zone, again with a slight ridge seen in scenario S06. The total values of the average noise levels, though, are higher in the park than in the Q-Zone. The park's ca-

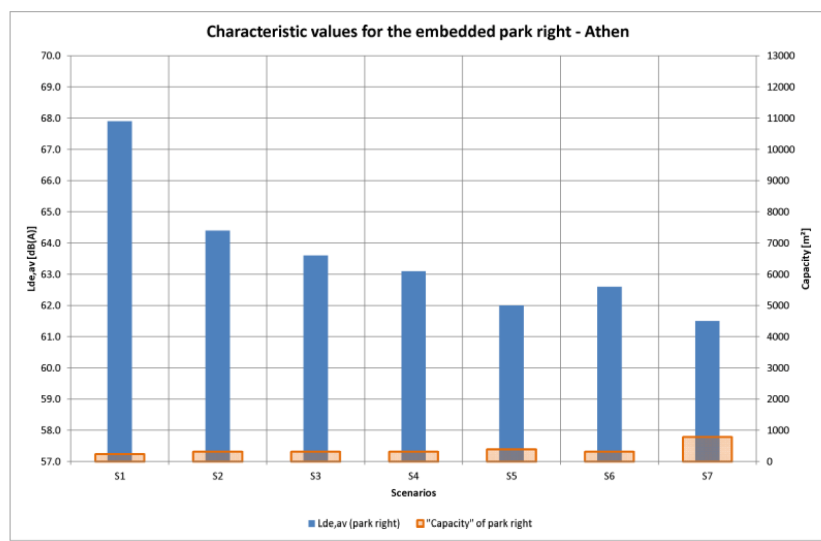

Figure 22: Average (arithmetic) noise level $\mathrm{L}_{d e, a v}$ and the capacity of the right hand side of the park in Athens in the various scenario configurations.

pacity shows an increasing trend starting from scenarios S01 through S07 with a notch in scenario S06.

This is the opposite trend compared to the trend of increasing noise levels. Values for the noise levels in the "complete" park, as well as at the surrounding area and also for the capacity of the "complete" park are shown in Table 5.

Figure 21 shows the average arithmetic noise levels $\mathrm{L}_{d e, a v}$ and the capacity values for each scenario, for the left side of the park. The trend of the average noise levels and the capacity is the same as for the complete park with the difference of overall reduced absolute values. Singlenumber values for the capacity in the park (left), the park surrounding and for the capacity (park, left) are given in Table 6.

Figure 22 hereafter shows the average arithmetic noise levels $\mathrm{L}_{d e, a v}$ and the capacity values for each scenario, for the right side of the park. The capacity shows a very moder- 
Table 7: $\mathrm{L}_{d e, a v}$ average values in the right hand side of the park and the park surrounding for each of the scenarios.

\begin{tabular}{lccccccc}
\hline Scenarios & S01 & S02 & S03 & S04 & S05 & S06 & S07 \\
\hline $\mathrm{L}_{d e, a v}[\mathrm{~dB}(\mathrm{~A})]$ (park right) & 67.9 & 64.4 & 63.6 & 63.1 & 62.0 & 62.6 & 61.5 \\
$\mathrm{~L}_{d e, a v}[\mathrm{~dB}(\mathrm{~A})]$ (surrounding) & 60.8 & 58.9 & 58.4 & 57.5 & 56.9 & 56.9 & 56.3 \\
“Capacity” $\left[\mathrm{m}^{2}\right]$ of park right & 237 & 316 & 316 & 316 & 395 & 316 & 790 \\
\hline
\end{tabular}

Table 8: Absolute and percent values for the amount of annoyed park visitors given separately for the left- and right- side of the park.

\begin{tabular}{cccccccc}
\hline Scenarios & S01 & S02 & S03 & S04 & S05 & S06 & S07 \\
\hline Annoyed visitors & 1986 & 1866 & 1849 & 1808 & 1784 & 1786 & 1760 \\
Park left [\%] & 66 & 62 & 62 & 60 & 59 & 60 & 59 \\
Annoyed visitors & 205 & 192 & 189 & 187 & 184 & 186 & 182 \\
Park right [\%] & 68 & 64 & 63 & 62 & 61 & 62 & 61 \\
\hline
\end{tabular}

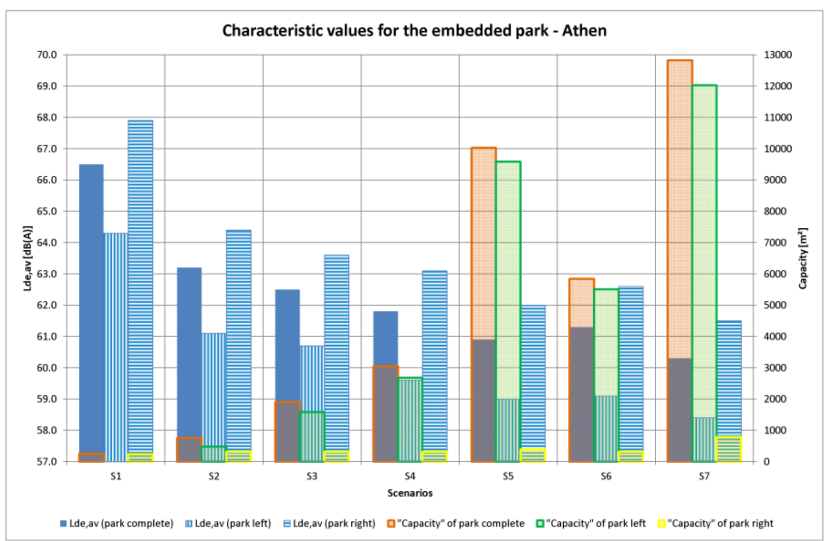

Figure 23: Comparison of the average (arithmetic) noise level $\mathrm{L}_{d e, a v}$ and the capacity of the right-, left- and the entire park area in Athens in various scenario configurations.

ate increase over the scenarios compared to the left side of the park. Single-number-values for the capacity in the park (right), the park surrounding and for the capacity (park, right) are given in Table 7.

To compare different cases, the average noise levels Lde, av and the capacity values are given in Figure 23 for the complete park from the left and right side, respectively. It can be observed that the values for the various scenarios follow the same trend in all three cases. The right hand side of the park shows the highest noise levels and lowest capacity. In relations to the left side of the park, the right side has very little capacity in all scenarios, thus the left side is the major contributor to the entire park's capacity.

The amount of HAP continuously decreases with each scenario, again with a slight ridge in scenario S06 (see Figure 24). Number and percent values for the amount of an-

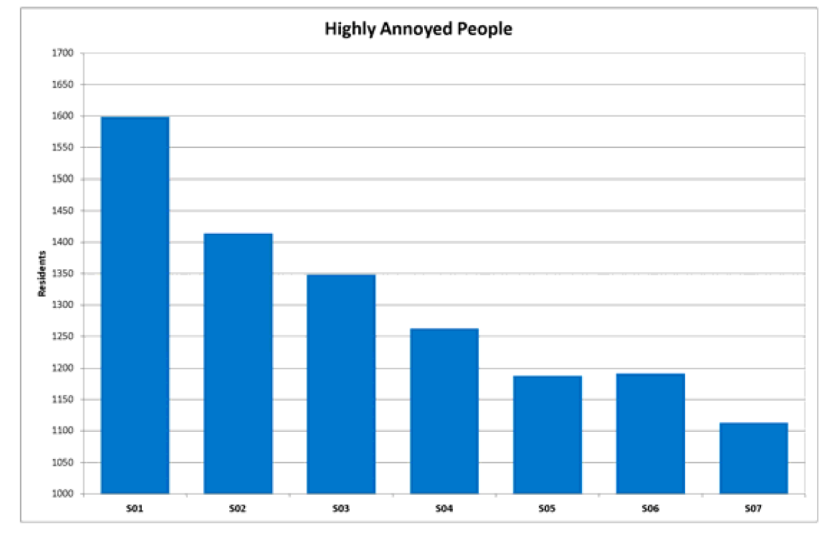

Figure 24: Amount of HAP in the various scenario configurations in the Q-Zone.

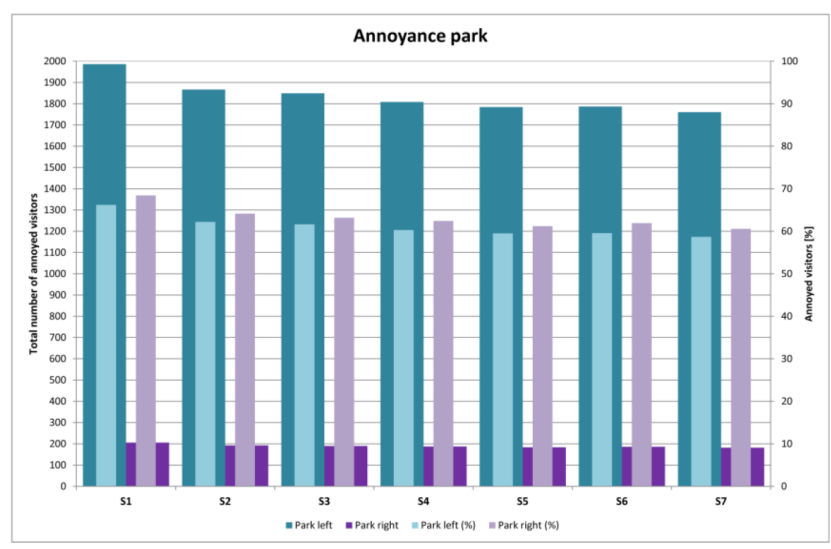

Figure 25: The total number and the percentage of annoyed people for the various scenario configurations in the Q-Zone in Athens.

noyed visitors in the left and right side of the park are given in Figure 25 and Table 8. 


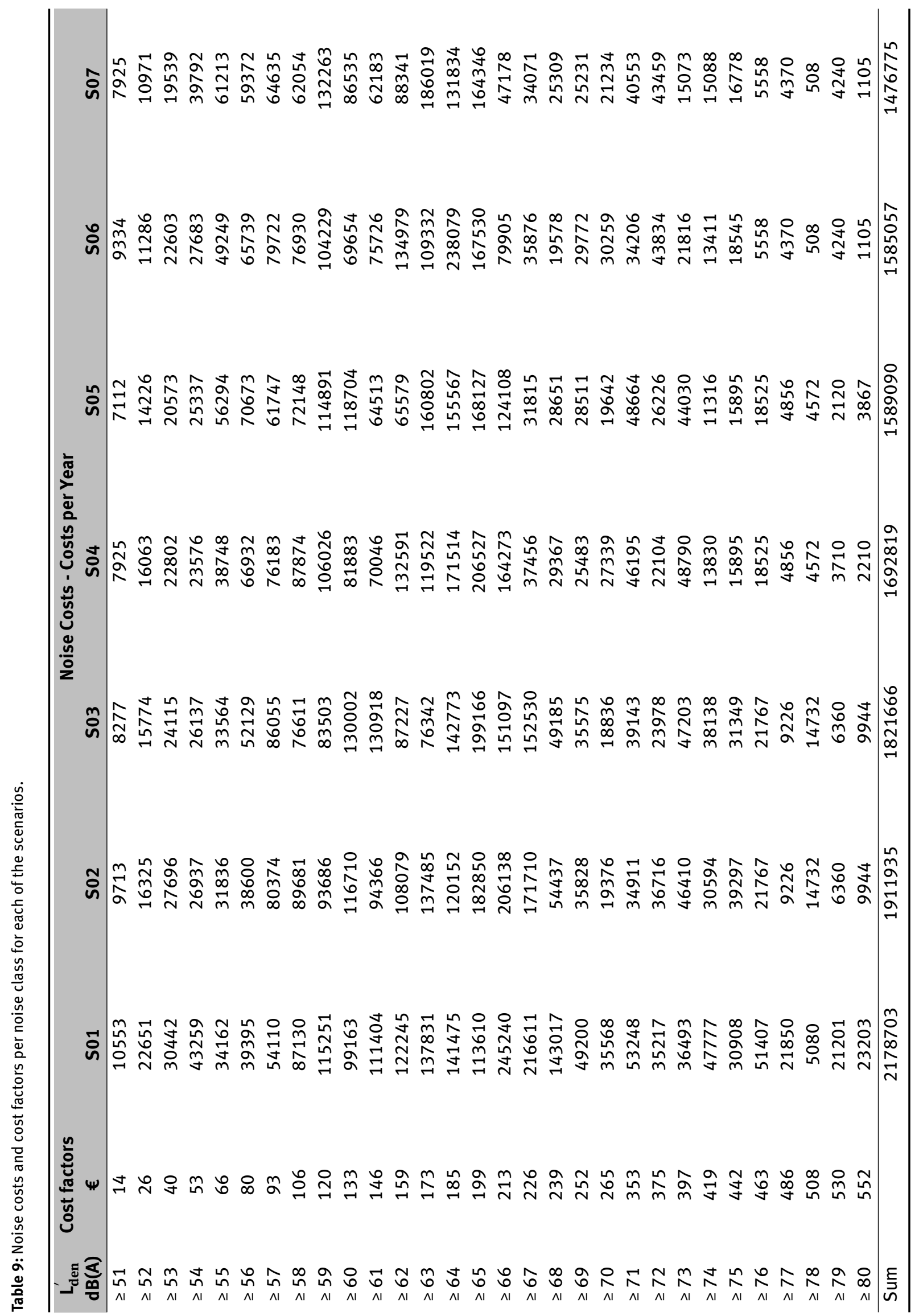




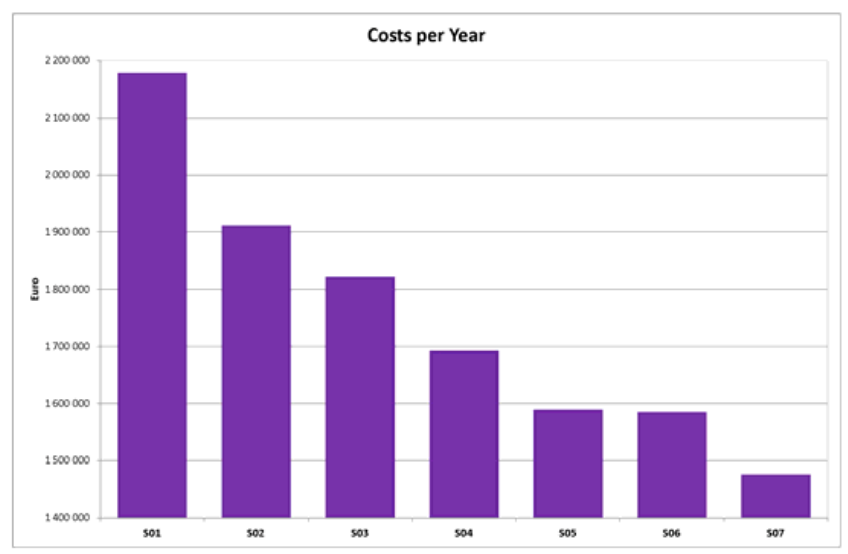

Figure 26: Noise costs for the various scenario configurations for the Q-Zone in Athens.

During the project's execution [14], it was determined that the general methodology identified in the HEATCO (Harmonised European Approaches for Transport COsting and Project Assessment) methodology [16] was implemented.

HEATCO's primary objective was the development of harmonised guidelines for project assessment on the EU level. This included the provision of a consistent framework for monetary valuation with transport costing. The choice of the HEATCO methodology for this study was primarily related to the proposals for dealing with noise within a health/annoyance type framework, and for noise costs, it was suggested that it would be possible to use country-specific values per person exposed to a certain level of noise. The suggested impact indicator, which should be reported alongside the monetary results, is the number of persons highly annoyed. All values include health effects and annoyance and central values comprise the WTP for reducing annoyance based on stated preference studies (see Working group on health and socioeconomic aspects, 2003). Annoyance was based on doseresponse functions, whereas monetary values were taken from the HEATCO surveys (see Navrud et al. 2006 [17]). High values include annoyance evaluation based on hedonic pricing as applied in the UNITE (see Bickel et al. 2003 [18]). The recommended calculation procedure from the HEATCO study is as follows:

- Step 1: Quantification of the number of persons exposed to certain noise levels (which should be available from noise calculations) for the Do-Minimum case and the Do- Something case.

- Step 2: Preparation of the cost factor table by increasing the cost factor according to the assumed country-specific GDP per capita growth for each year of the analysis.

- Step 3: Calculation of impacts (multiply percentage of highly annoyed persons by number of persons exposed) and costs (multiply cost per person by number of persons exposed) for both cases.

- Step 4: Subtraction of total costs for the DoSomething case from Do-Minimum case.

- Step 5: Reporting of costs and impacts (change in number of people highly annoyed).

Noise costs are reduced with each of the scenarios above. In the base case scenario S1, the noise costs almost reach $2.2 \mathrm{~m} €$ per year, whereas in scenario $\mathrm{S} 7$ they are reduced to just under 1.5 m€per year, leading to an annual reduction of approximately $700,000 €$.

The noise costs are depicted in a bar chart for each of the seven scenarios in Figure 26. The corresponding table with noise classes in $1 \mathrm{~dB}$ steps and cost factors for each noise class is given in Table 9 hereafter.

\section{Conclusions}

With the above Q-Zone scenario configurations, it has been shown that the average noise levels in the Q-Zone and the park can slightly be reduced and the park capacity increased. Measures with a special focus on the reduction of conventional PTWs were included. The emission values of various PTWs were derived, from the known values of car emissions and from past measurements, in the form of a correction function as a function of speed. These derived values were then used to perform the simulation analysis on the effects of the overall noise levels by shifting the proportion of conventionally and electrically driven PTWs. As a result, the noise difference maps show slight noise reductions, while it is more pronounced if other measures are included, such as speed limits. Additional measures, such as increasing the proportion of low noise cars and reducing the noise level of the railway by $5 \mathrm{~dB}$, enhances this positive effect. The effects of these noise reduction measures have on both noise rating models, the amount of HAP and on the number of annoyed park visitors, was predicted. As expected, the amount of HAP and the number of park visitors are correlated with the reduction of overall noise level. This suggests that the decrease trend of noise level reduction seen throughout the different scenarios is also reflected in the amount of HAP and the number of annoyed park visitors. Finally, the noise costs were estimated, which appear to decrease with the decreasing average noise levels. Thus, scenario S07 contains the least 
noise costs whereas the base scenario S01 shows the highest noise costs. Costs of introducing the new measures were not considered.

Acknowledgement: This study has been performed within the context of the EU research project CITYHUSH, Acoustically Green Road Vehicles and City Areas,

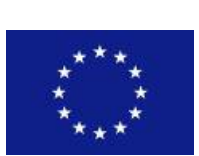
financed by the $7^{\text {th }}$ Framework Programme of the European Union under the contract $\mathrm{N}^{\circ}$ SPC8-GA-2009-233655). http://www.cityhush.eu/

\section{References}

[1] DIRECTIVE 2002/49/EC OF THE EUROPEAN PARLIAMENT AND OF THE COUNCIL of 25 June 2002 relating to the assessment and management of environmental noise.

[2] K. Vogiatzis, P. Vanhonacker, Noise reduction in urban LRT networks by combining track based solutions, Science of the Total Environment, DOI: 10.1016/j.scitotenv.2015.05.060, Article in Press.

[3] G. Kouroussis, N. Pauwels, P. Brux, C. Conti, O. Verlinden, A numerical analysis of the influence of tram characteristics and rail profile on railway traffic ground-borne noise and vibration in the Brussels Region, Science of the Total Environment, Volume 482-483, Issue 1, 1 June 2014, Pages 452-460.

[4] G. Licitra, E. Ascari, Gden: An indicator for European noise maps comparison and to support action plans Science of the Total Environment 482, 411-419.

[5] G. Licitra, E. Ascari, G. Brambilla, Comparative Analysis of Methods to Estimate Urban Noise Exposure of Inhabitants Acta Acustica united with Acustica 98 (4), 659-666

[6] G. Licitra, P. Gallo, E. Rossi, G. Brambilla, A novel method to determine multi-exposure priority indices tested for Pisa action plan Applied Acoustics 72 (8), 505-510.

[7] F. D'Alessandro, S. Schiavoni, A review and comparative analysis of European priority indices for noise action plans, Science of The Total Environment, Volumes 518-519, 15 June 2015, Pages 290-301.

[8] K. Vogiatzis, M. Paviotti, D 3.5.3 Noise effect of restrictions on motorcycle use, EU research project CITYHUSH, Acoustically Green Road Vehicles and City Areas, FP7-233655,WP 3.5 Noise and vibration control at source - Acoustically green vehicles/Definition of a noise $\&$ annoyance standard for motorcycles in the urban environment, 10/2010.
[9] K. Vogiatzis, M. Paviotti, D 3.5.2: Motorcycle noise evaluated in the developed noise score models for outdoor noise and indoor noise, EU research project CityHush, Acoustically Green Road Vehicles and City Areas, FP7-233655, WP 3.5 Noise and vibration control at source - Acoustically green vehicles/Definition of a noise $\&$ annoyance standard for motorcycles in the urban environment, 11/2011.

[10] M. Paviotti, K. Vogiatzis, One the outdoor annoyance from scooter and motorbike noise in the urban environment, Science of the Total Environment (STOTEN) 130 (2012) 223-230.

[11] M. Paviotti, K.E. Vogiatzis, Noise and annoyance from motorbikes, scooters and mopeds in urban areas, $19^{\text {th }}$ International Congress on Sound and Vibration ICSV 19, 08-12 July 2012, Vilnius Lithuania.

[12] E.M. Salomons, S.A. Janssen, D 2.2.1: Refined noise score rating model for residents, EU research project CityHush, Acoustically Green Road Vehicles and City Areas, FP7-233655, WP 2.2 Noise score rating models and annoyance/Development of the noise residents inside, 06/2011.

[13] S.A. Janssen, E. Salomons, D 2.1.1: Preliminary noise score rating model for the outdoors EU research project CityHush, Acoustically Green Road Vehicles and City Areas, FP7-233655, WP 2.1 Noise score rating models and annoyance/Noise score rating method for the outdoors, $12 / 2010$.

[14] G. Parry, M. Petz, D 2.3.1: Cost/benefit analysis of mitigation measures against potential benefits for local residents and park visitors, EU research project CityHush, Acoustically Green Road Vehicles and City Areas, FP7-233655, WP 2.3 Noise score rating models and annoyance/Cost/benefit analysis of Q-Zones, 01/2012.

[15] CadnaA, software for calculation, presentation, assessment and prediction of environmental noise, Datakustik $\mathrm{GmbH}$, Greifenberg.

[16] HEATCO, Developing Harmonised European Approaches for Transport Costing and Project Assessment, Final Technical Report, 15 December 2006.

[17] S. Navrud, Y. Trædal, A. Hunt, A. Longo, A. Greemann, C. Leon, R. Espino, R. Markovitssomogyi, F. Meszaros, (2006): Economic values for key impacts valued in the Stated Preference surveys, HEATCO Deliverable 4.

[18] P. Bickel, S. (IER) Schmid, J. Tervonen, K. Hämekoski, T. Otterström, P. (EKONO) Anton, R. Enei, G. (ISIS) Leone, P. van Donselaar, H. (NEI) Carmigchelt, (2003): Environmental Marginal Cost Case Studies, UNITE Deliverable 11, Stuttgart 2003, http: //www.its.leeds.ac.uk/projects/unite/downloads/D11.pdf. 